\title{
Validation of 3-D Ice Accretion Measurement Methodology for Experimental Aerodynamic Simulation
}

\author{
Andy P. Broeren ${ }^{1}$ and Harold E. Addy, $\mathrm{Jr}^{2}$ \\ NASA John H. Glenn Research Center, Cleveland, Ohio 44135 USA \\ Sam Lee ${ }^{3}$ \\ Vantage Partners, LLC, Cleveland, Ohio 44135 USA \\ and \\ Marianne C. Monastero ${ }^{4}$ \\ University of Illinois at Urbana-Champaign, Urbana, Illinois, 61801 USA
}

\begin{abstract}
Determining the adverse aerodynamic effects due to ice accretion often relies on dry-air wind-tunnel testing of artificial, or simulated, ice shapes. Recent developments in iceaccretion documentation methods have yielded a laser-scanning capability that can measure highly three-dimensional features of ice accreted in icing wind tunnels. The objective of this paper was to evaluate the aerodynamic accuracy of ice-accretion simulations generated from laser-scan data. Ice-accretion tests were conducted in the NASA Icing Research Tunnel using an 18-inch chord, 2-D straight wing with NACA 23012 airfoil section. For six iceaccretion cases, a 3-D laser scan was performed to document the ice geometry prior to the molding process. Aerodynamic performance testing was conducted at the University of Illinois low-speed wind tunnel at a Reynolds number of $1.8 \times 10^{6}$ and a Mach number of 0.18 with an 18-inch chord NACA 23012 airfoil model that was designed to accommodate the artificial ice shapes. The ice-accretion molds were used to fabricate one set of artificial ice shapes from polyurethane castings. The laser-scan data were used to fabricate another set of artificial ice shapes using rapid prototype manufacturing such as stereolithography. The iced-airfoil results with both sets of artificial ice shapes were compared to evaluate the aerodynamic simulation accuracy of the laser-scan data. For four of the six ice-accretion cases, there was excellent agreement in the iced-airfoil aerodynamic performance between the casting and laser-scan based simulations. For example, typical differences in iced-airfoil maximum lift coefficient were less than $3 \%$ with corresponding differences in stall angle of approximately one degree or less. The aerodynamic simulation accuracy reported in this paper has demonstrated the combined accuracy of the laser-scan and rapid-prototype manufacturing approach to simulating ice accretion for a NACA 23012 airfoil. For several of the ice-accretion cases tested, the aerodynamics is known to depend upon the small, threedimensional features of the ice. These data show that the laser-scan and rapid-prototype manufacturing approach is capable of replicating these ice features within the reported accuracies of the laser-scan measurement and rapid-prototyping method; thus providing a new capability for high-fidelity ice-accretion documentation and artificial ice-shape fabrication for icing research.
\end{abstract}

\footnotetext{
${ }^{1}$ Research Aerospace Engineer, Icing Branch, 21000 Brookpark Rd., MS 11-2, Associate Fellow AIAA.

${ }^{2}$ Research Aerospace Engineer, Icing Branch, 21000 Brookpark Rd., MS 11-2, Associate Fellow AIAA.

${ }^{3}$ Engineer IV, Icing Branch, 21000 Brookpark Rd., MS 11-2, Senior Member AIAA.

${ }^{4}$ Graduate Research Assistant, now at Rensselaer Polytechnic Institute, Department of Mechanical, Aerospace and Nuclear Engineering, Center for Flow Physics and Control, Watervliet Facility, $1108^{\text {th }}$ St., Troy, NY 12180, Student Member AIAA.
} 


\section{Nomenclature}

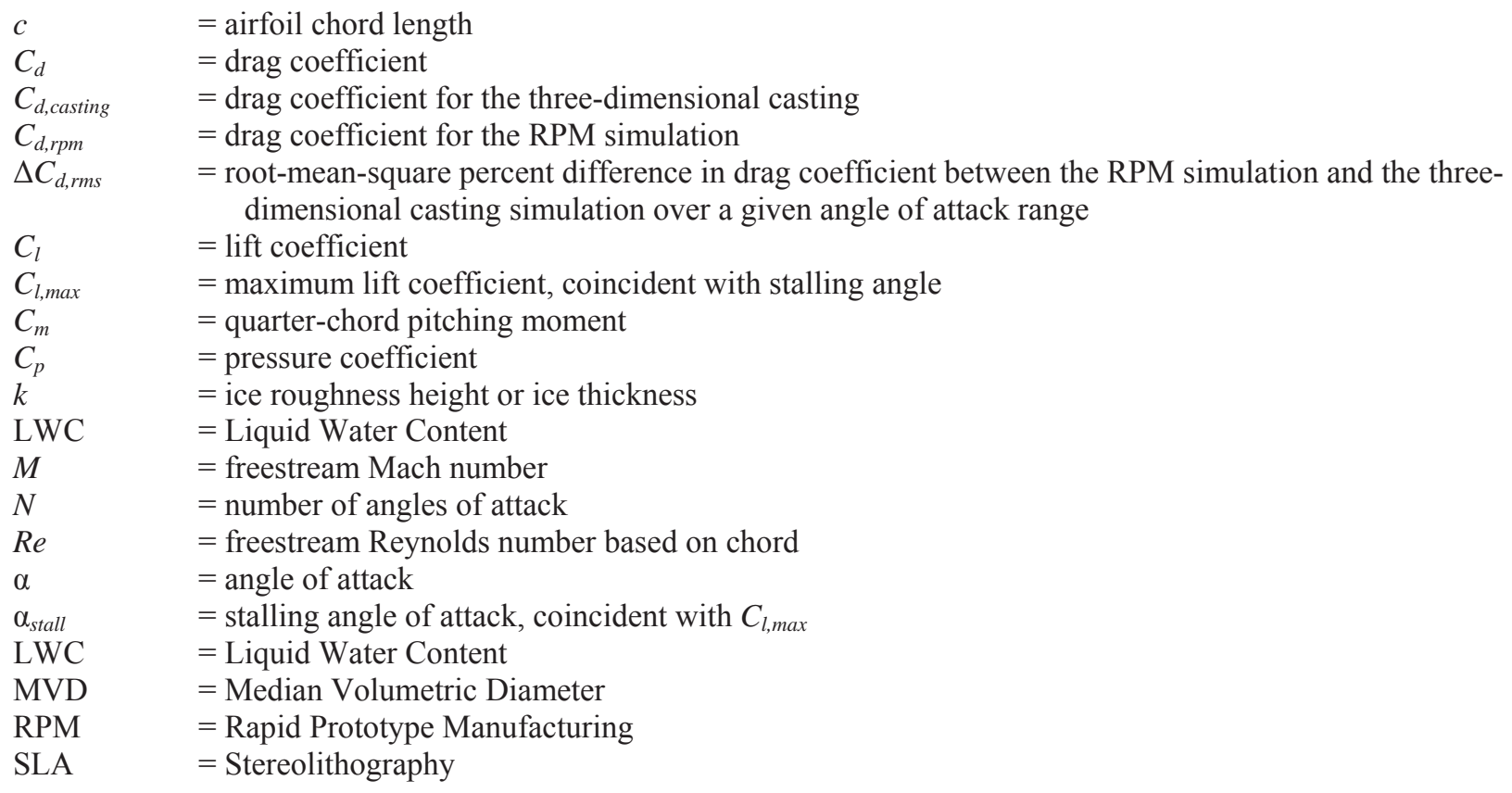

\section{Introduction}

Ice accretion and its aerodynamic effect on airfoil and wing performance are important to the continued design, certification and safe operation of aircraft in the icing environment. Icing wind tunnels are a critical engineering tool for simulating natural ice accretion on aircraft surfaces. As described by Lee et al., ${ }^{1}$ the chief product of such facilities is the ice accretion that forms on various test articles ranging from airplane wings, rotor blades, engine inlets, radomes and other flight hardware. Bosetti et al. ${ }^{2}$ discuss many important aspects of documenting ice-shape characterization. They point out that ice shapes are often used by other groups for follow-on computational or experimental aerodynamic studies; development of design criteria or requirements; engineering tool development, improvement or validation. Therefore, documentation of the resulting ice accretion is a key piece of data in icingwind-tunnel tests. In a companion paper, Lee et al. ${ }^{3}$ describe continued progress on the development of a 3-D iceaccretion measurement methodology using laser-scanning systems, including a geometric evaluation of its accuracy. This paper focuses on an aerodynamic approach for evaluating the accuracy of ice accretion measured using the laser-scanning approach on a subscale straight wing.

Lee et al. ${ }^{1}$ describe the documentation of ice-accretion geometries in icing-wind-tunnel tests using many different techniques. These techniques include standard (qualitative) photography, quantitative photography, tracings, and various molding and casting techniques using impression foam, wax, plaster and other materials. The best current technology for capturing three-dimensional features of ice accretion is the mold and casting method. This has been used for many years, but was improved at NASA Glenn (then Lewis) during the 1980s using more robust materials to improve accuracy and durability. ${ }^{4}$ The main disadvantages to the mold and casting method are that it can be time consuming both during the icing test and in post-test production. Cost can be significant in some cases but generally scales with the size of the ice accretion to be documented. There is no electronic or digitized record of the ice-accretion geometry, only a physical casting. Additional measurements are required in order to generate quantitative information about the ice-accretion geometry. Lee et al. ${ }^{3}$ report on recent developments with laser-scanning based methods that are capable of directly measuring and digitally archiving the 3-D features of iceaccretion geometry.

One motivation for ice-accretion documentation is to evaluate the resulting aerodynamic effect. According to Broeren et al. ${ }^{5}$ the most common way to acquire iced-airfoil and wing data is to use geometric representations of ice accretion in a dry-air wind tunnel or in flight. These geometric representations are often referred to as "artificial ice shapes" or "ice-accretion simulations." The highest fidelity ice-accretion simulations are castings developed from the molding process described in the previous paragraph. These ice-accretion castings maintain the major features of the ice, including the detailed surface roughness and the spanwise and chordwise variations. Typically, these castings are attached to wings and airfoils, and instrumented to obtain high-fidelity aerodynamic data. ${ }^{6-11}$ This is an 
expensive process and not practical for many situations, but does generate benchmark data for iced-airfoil and wing research. Broeren et al. ${ }^{5}$ describe a recently completed comprehensive study of aerodynamic simulation of ice accretion that utilized the mold and casting method as benchmark data in order to evaluate the aerodynamic accuracy of lower-fidelity ice-accretion simulations. For some cases such as initial roughness, spanwise ridges and streamwise ice shapes, it was found that the fine geometric details can be important to the resulting aerodynamics. Therefore, it is important to understand the accuracy to which 3-D ice-accretion geometry can be measured using new tools such as laser scanning described by Lee et al. ${ }^{3}$

The objective of the current study is to evaluate the aerodynamic accuracy of ice-accretion simulations generated from laser-scan data. Ice-accretion tests were conducted in the NASA Icing Research Tunnel (IRT) using an 18-inch chord, 2-D straight wing with NACA 23012 airfoil section. Several different types of ice accretions were generated. For the selected cases, a 3-D laser scan was performed to document the ice-accretion geometry prior to the molding process. Artificial ice shapes were fabricated for aerodynamic testing in the University of Illinois lowspeed wind-tunnel. The artificial ice shapes were attached to the leading edge of an 18-inch chord NACA 23012 airfoil model. The ice-accretion molds were used to fabricate one set of artificial ice shapes from polyurethane castings. The laser-scan data were used to fabricate artificial ice shapes using rapid-prototype manufacturing (RPM) such as stereolithography. Aerodynamic performance testing was conducted at a Reynolds number of $1.8 \times 10^{6}$ and a Mach number of 0.18 . The iced-airfoil results with both sets of artificial ice shapes were compared to evaluate the aerodynamic simulation accuracy of the laser-scan data. It should be noted that the aerodynamic comparisons amount to a combined evaluation of not only the laser-scanning measurement method, but also the accuracy of the RPM used to generate the artificial ice shapes. For the purposes of this paper, uncertainties in the scan data and manufacturing tolerances in the RPM are combined into the resulting artificial ice shape. The companion paper by Lee et al. ${ }^{3}$ contains more information on the uncertainty in the scan data alone.

\section{Experimental Methods and Apparatus}

\section{A. Aerodynamic Experiments}

All aerodynamic testing was performed using the low-speed, low-turbulence wind tunnel at the University of Illinois with the experimental apparatus described by Broeren et al. ${ }^{5}$ The wind tunnel has a 33.6-in. (0.85-m) by 48in. (1.2-m) test section capable of speeds up to Mach 0.20. An 18-in. (0.46-m) chord NACA 23012 airfoil model was designed with interchangeable leading edges that accommodated the various ice simulations. There was a baseline leading edge having the NACA 23012 profile that was used to document the un-iced, or clean, airfoil performance, and there were two ice leading edges with truncated nose geometry that allowed for the attachment of the ice simulations. The artificial ice shapes bolted onto the ice leading edges and thus had a rigid, repeatable mounting system. Figure 1 shows the NACA 23012 model installed in the University of Illinois wind tunnel. The model had a main chordwise row of pressure taps, a secondary chordwise row, and a set of spanwise taps on the upper surface. Both sets of artificial ice shapes (castings and RPM shapes) were also instrumented with static pressure taps.

The model lift and pitching-moment data were acquired from a force balance and by integration of airfoil surface static pressures measured by an electronically scanned pressure system. Good agreement between these methods was generally obtained. Locating and installing pressure orifices in and around 3-D ice features sometimes led to spurious $C_{p}$ points on the artificial ice shape at certain angles of attack. These spurious data could affect the lift and pitching-moment coefficients determined from integrated surface pressure data. For this reason, and for consistency with the results presented in Broeren et al. ${ }^{5}$ the lift and pitching moment data for the clean configuration were obtained from the surface pressures, whereas the data reported for the iced configurations were obtained from the force balance in this paper. Momentum-deficit methods were used to compute the drag coefficient from totalpressure measurements collected by a traversable wake rake. This wake rake is shown downstream of the model in Fig. 1. Surface-oil flow visualization was also conducted for selected cases. A light coat of mineral oil treated with fluorescent dye was applied to the surface of the model in the region of interest. The tunnel flow condition was then set and maintained for a period of time sufficient to allow the local wall shear stress to cause the oil to flow on the surface. The resulting oil-flow patterns indicated boundary-layer transition and regions of attached and separated flow. Monastero and Bragg ${ }^{12,13}$ describe pressure-sensitive paint (PSP) measurements that were also conducted for some of the artificial ice-shape configurations.

Busch, ${ }^{14}$ Monastero ${ }^{12}$ and Broeren et al. ${ }^{5}$ also provide more details about the experimental setup, including the data uncertainty analysis. The experimental uncertainties were calculated for 20:1 odds using the methods of Kline and McClintock ${ }^{15}$ and Coleman and Steele. ${ }^{16}$ Sample uncertainties are provided in Table 1 for the clean-model configuration. These uncertainties were acceptable for this investigation. The relative uncertainty in the pitching- 
moment coefficient appears to be large because the reference value is small. The methods of Allen and Vincenti ${ }^{17}$ and Barlow, Rae and Pope ${ }^{18}$ were used to correct the angle of attack, lift coefficient, pitching-moment coefficient and drag coefficient for wind-tunnel wall boundary effects. All data were collected at a Reynolds number of $R e=$ $1.8 \times 10^{6}$ and a corresponding Mach number of $M=0.18$.

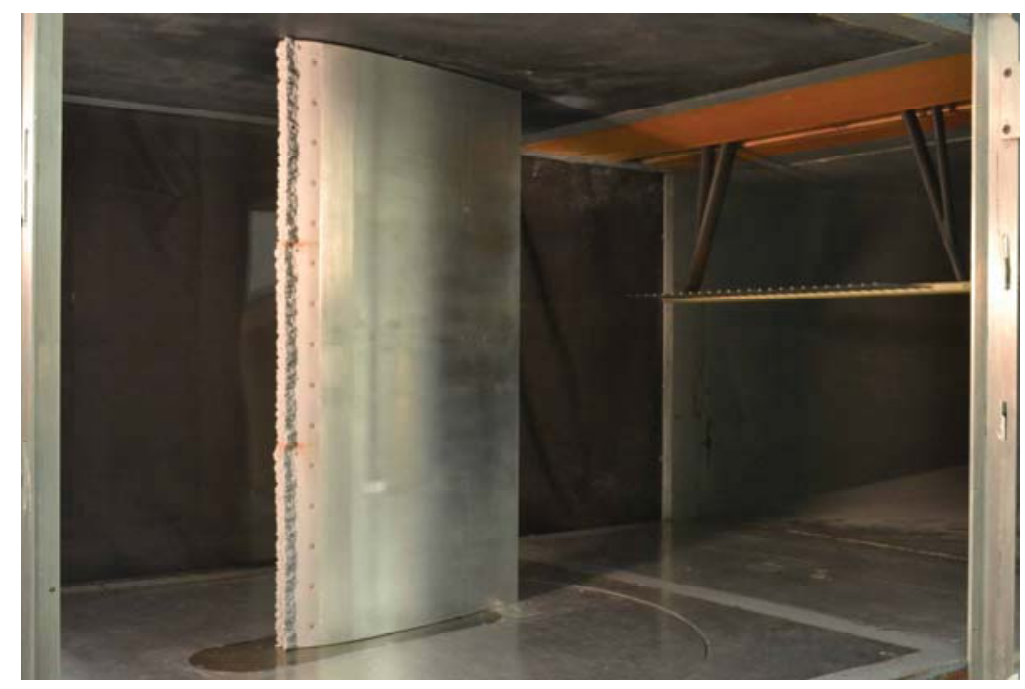

Figure 1. NACA 23012 airfoil model installed in the University of Illinois wind-tunnel test section with artificial ice shape installed on leading edge.

Table 1 Estimated Experimental Uncertainties.

\begin{tabular}{cccc}
\hline \hline Aerodynamic Quantity & Reference Value & Absolute Uncertainty & Relative Uncertainty \\
\hline$\alpha$ & 4.16 deg. & \pm 0.02 deg. & $\pm 0.48 \%$ \\
$C_{l}$ Balance & 0.548 & \pm 0.00019 & $\pm 0.35 \%$ \\
$C_{m}$ Balance & -0.0020 & \pm 0.00023 & $\pm 12.1 \%$ \\
$C_{p}$ & -0.962 & \pm 0.0045 & $\pm 0.47 \%$ \\
$C_{d}$ Wake & 0.0071 & \pm 0.00014 & $\pm 1.9 \%$ \\
\hline \hline
\end{tabular}

\section{B. Ice-Accretion Experiments}

Ice-accretion tests were conducted in the NASA Icing Research Tunnel (IRT) using an 18-inch chord, 2-D straight wing with NACA 23012 airfoil section. Several different types of ice accretions were generated, and a subset of these were selected for aerodynamic evaluation. Table 2 provides the aerodynamic and icing cloud conditions for the selected cases. The first column, "Ice-Shape Classification" refers to the aerodynamic classification described by Bragg et al. ${ }^{19}$ For this investigation, there were two roughness shapes, two streamwise ice shapes, one spanwise-ridge ice shape and one horn ice shape. For these ice shapes listed in Table 2, a 3-D laser scan was performed to document the ice-accretion geometry prior to the molding process. The ice-accretion molds were used to fabricate one set of artificial ice shapes from polyurethane castings. Monastero ${ }^{12}$ provides a detailed description of the mold-and-casting process used in this research. The laser-scan data were used to fabricate the RPM artificial ice shapes. Lee et al. ${ }^{3}$ provide a detailed description of process used to develop the RPM artificial ice shapes from the laser-scan data. Care was taken to ensure that the castings and RPM shapes corresponded to identical spanwise locations on the IRT model. The spanwise length of the finished artificial ice shapes was limited to one-third of the aerodynamic model span, so that three identical sections were required to cover the span of the model in the Illinois wind tunnel. The artificial ice shapes had pressure taps installed at equivalent locations for the castings and RPM shapes. Figure 2 shows pictures of the instrumented segments of the ED1977 streamwise ice shape simulations for comparison. 
In all cases the RPM shapes were manufactured using stereolithography (SLA). Data provided by the manufacturer indicated an accuracy of \pm 0.015 inches with a minimum layer thickness of 0.005 inches. The manufacturer also stated that feature sizes less than 0.025 inches in size were not guaranteed to build with SLA. In the case of the ED1983 shape, an additional method, High-Density PolyJet was used. The objective here was to evaluate any difference in the methods used for rapid prototyping. Since the ED1983 shape had the smallest roughness features, this was determined to be the best candidate for this evaluation. Data provided by the manufacturer indicated an accuracy of \pm 0.005 inches with a minimum layer thickness of 0.0006 inches. The minimum feature size for High-Density PolyJet was 0.012 inches.

As indicated in Table 2, a total of six different ice accretions were selected for aerodynamic testing following the aerodynamic classifications described by Bragg et al. ${ }^{19}$ Graphical information for each case is shown in Figs. 3-8. The section cuts shown in the figures were extracted from the laser-scan data for each configuration. In the case of the artificial ice shapes, the laser scan was acquired with the artificial ice shape bolted to the leading edge of the NACA 23012 wind-tunnel model. Therefore, the laser-scan data accurately represent the geometry as it was tested in the aerodynamic wind tunnel. Also shown for reference is a section cut extracted from the original ice accretion scan. Each figure shows a 3-D rendering of the artificial ice shape solid model used for production of the RPM shapes. Finally, a photograph of the ice accretion is also included.

Two cases of ice roughness were selected to evaluate the accuracy of the laser-scan and RPM approach to developing artificial ice shapes. The ED1974 case was a glaze-ice roughness while ED1983 was a rime-ice roughness. The latter had very small roughness feather features virtually invisible in Fig. 4 that were thought to be challenging to the laser-scanning and RPM processes. For both cases, the ice thickness was very small and, as a result, it is difficult to meaningfully compare the section cuts in the regions dominated by roughness The ice was thicker (and much smoother) in the region of the stagnation point. The section cuts in Fig. 3 for the ED1974 case compare favorably in this region. In contrast, the section cuts in Fig. 4 for the ED1983 case indicate that there was a significant decrease in stagnation point ice thickness for the casting configuration. This discrepancy was attributed to misalignment of the ice mold and leading-edge geometry during the casting process. Lee et al. ${ }^{3}$ also note that the cast shapes were often smaller than the RPM shapes and the original ice accretion thus indicating shrinkage during the mold and casting process. For the ED1983 case, there is a more favorable comparison among both RPM shapes with the ice accretion. More discussion of the roughness features is included with presentation of the aerodynamic data in the next section.

Two different streamwise ice shape cases were selected to evaluate the accuracy of the laser-scan and RPM approach. The ED1966 case shown in Fig. 5 was characterized by a main ice shape located near the airfoil leading edge with rime feathers downstream. These rime feather features were small, but still visible in the Fig. 5 images. The ED1977 case shown in Fig. 6 was characterized by a main ice shape that was more conformal to the airfoil leading edge with much larger rime feather features. The larger rime feathers also extended farther downstream, both effects being attributable to the larger drop size $(M V D=30 \mu \mathrm{m})$ used to form the ice accretion. The section cuts shown in Figs. 5 and 6 demonstrate good agreement among the artificial ice-shape configurations with the original ice accretion.

A spanwise-ridge ice shape was also selected to evaluate the accuracy of the laser-scan and RPM approach. The ED1967 case shown in Fig. 7 was formed with an electrothermal surface heater mounted to the model leading edge. Icing conditions and heater settings were adjusted to create conditions where water flowed downstream over the heater on both the upper and lower surfaces of the model. The objective was to simulate the development of a spanwise-ridge ice accretion that may result from a thermal ice-protection system. The images in Fig. 7 illustrate the spanwise ridges that formed on both upper and lower surfaces and that there was good agreement among the iceshape configurations with the ice accretion itself. The electrothermal surface heater did affect the laser-scan data and resulting artificial ice shapes which Lee et al. ${ }^{3}$ explain in their paper.

Finally, a horn ice shape was selected to evaluate the accuracy of the laser-scan and RPM approach. The ED1978 case shown in Fig. 8 is a typical glaze ice accretion with both upper- and lower-surface horns. The section cuts do indicate some differences in the upper-surface horn geometry for the casting configuration relative to the iceaccretion data and RPM configurations. The upper-surface horn of the casting was slightly shorter and more rounded. Also, there was a significant amount of ice missing from the casting near the base of the upper-surface horn at $x / c \approx 0.0, y / c \approx 0.025$. In the case of hand tracing, such differences might simply be attributable to spanwise variations in the ice accretion, illustrated in the accompanying images. This explanation is unsatisfactory in this case, since extracting section cuts from the laser-scan data is much more precise than hand tracing. As Lee et al. ${ }^{3}$ describe, the measurements indicate that were was some shrinkage and warpage in the casting that led to the geometric differences shown in Fig. 8. Lee et al. ${ }^{3}$ provide a more detailed description and analysis of the geometric differences between the laser-scan and RPM shapes and the corresponding casting configurations. 
Table 2 Summary of IRT Test Conditions for Ice Shapes Selected for Aerodynamic Evaluation.

\begin{tabular}{ccccccccc}
\hline \hline $\begin{array}{c}\text { Ice-Shape } \\
\text { Classification }\end{array}$ & $\begin{array}{c}\text { IRT Run } \\
\text { Number }\end{array}$ & $\begin{array}{c}\text { Airspeed } \\
(\text { knots })\end{array}$ & $\begin{array}{c}\alpha \\
(\text { deg. })\end{array}$ & $\begin{array}{c}\text { MVD } \\
(\mu \mathrm{m})\end{array}$ & $\begin{array}{c}\text { LWC } \\
\left(\mathrm{g} / \mathrm{m}^{3}\right)\end{array}$ & $\begin{array}{c}\text { Total Temp. } \\
\left({ }^{\circ} \mathrm{F} /{ }^{\circ} \mathrm{C}\right)\end{array}$ & $\begin{array}{c}\text { Static Temp. } \\
\left({ }^{\circ} \mathrm{F} /{ }^{\circ} \mathrm{C}\right)\end{array}$ & $\begin{array}{c}\text { Spray Time } \\
(\mathrm{min} .)\end{array}$ \\
\hline Roughness 1 & ED1974 & 200 & 2.0 & 15 & 0.75 & $28.0 /-2.2$ & $18.5 /-7.5$ & 0.5 \\
Roughness 2 & ED1983 & 200 & 2.0 & 30 & 0.40 & $0.0 /-17.8$ & $-9.5 /-23.1$ & 1.0 \\
Streamwise 1 & ED1966 & 175 & 5.0 & 15 & 0.30 & $0.0 /-17.8$ & $-7.3 /-21.8$ & 5.0 \\
Streamwise 2 & ED1977 & 200 & 2.0 & 30 & 0.40 & $0.0 /-17.8$ & $-9.5 /-23.1$ & 5.0 \\
Spanwise Ridge & ED1967 & 175 & 1.0 & 15 & 0.64 & $24.0 /-4.4$ & $16.8 /-8.4$ & 9.5 \\
Horn & ED1978 & 200 & 2.0 & 15 & 0.75 & $28.0 /-2.2$ & $18.5 /-7.5$ & 5.0 \\
\hline \hline
\end{tabular}
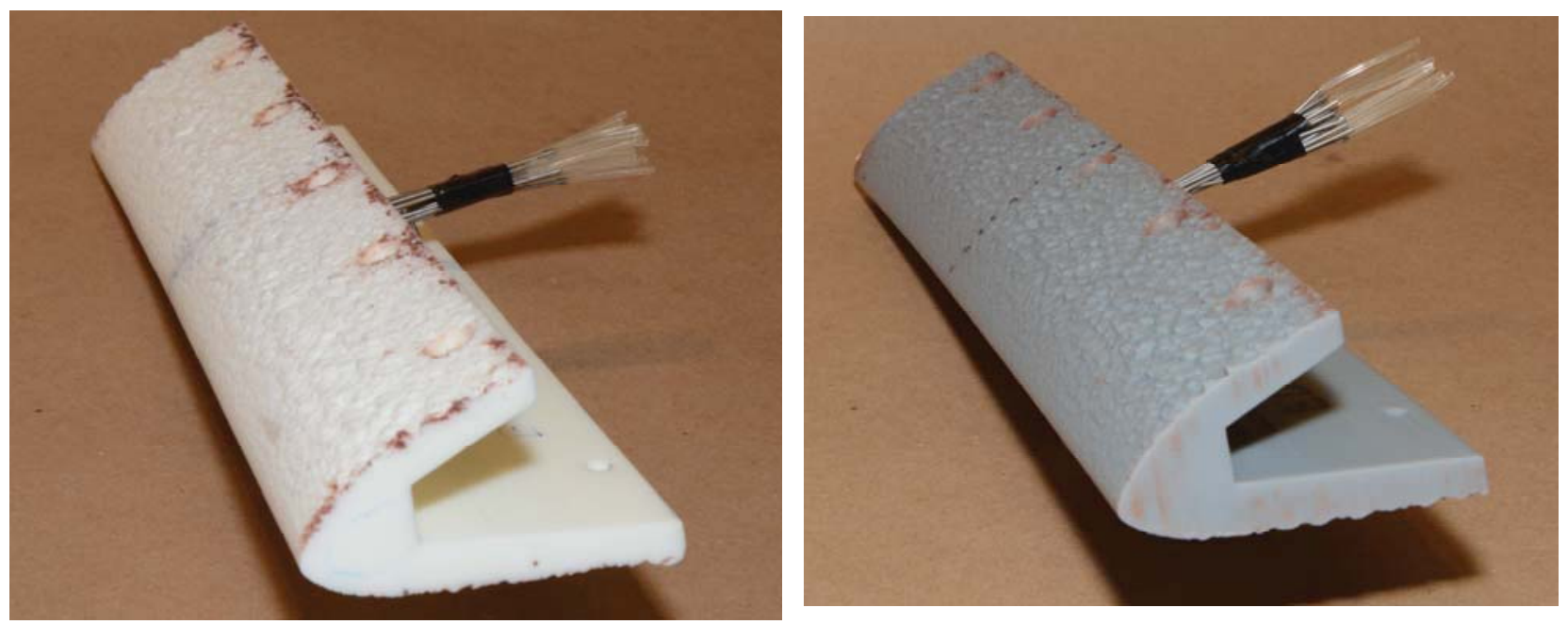

Figure 2. Pressure tap segments of ED1977 streamwise ice-shape simulations; left—casting, right-RPM artificial ice shape. 

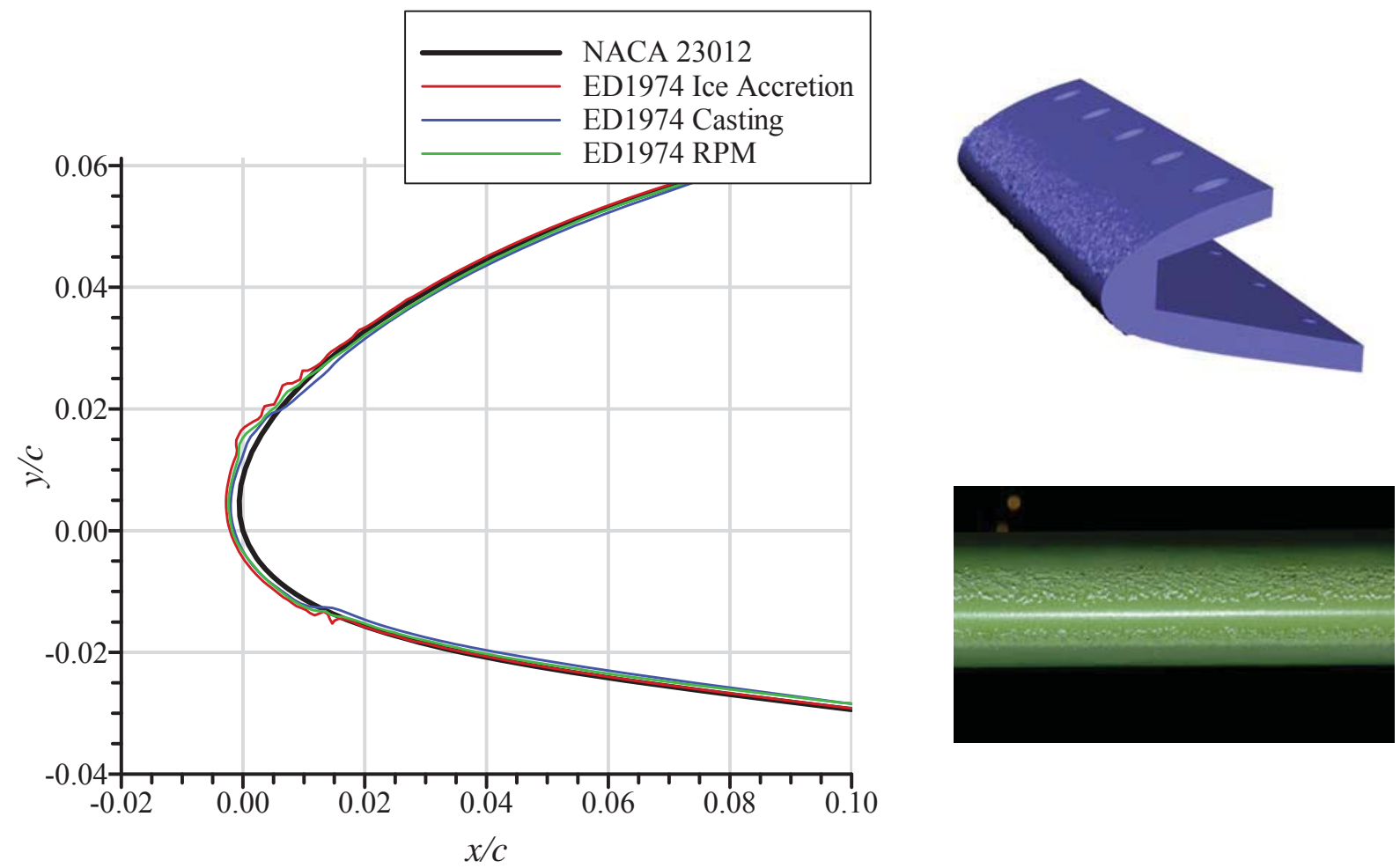

Figure 3. ED1974 roughness ice shape: section cuts extracted from laser-scan data (left); rendering of RPM artificial ice shape (top right) and ice-accretion photograph (bottom right).
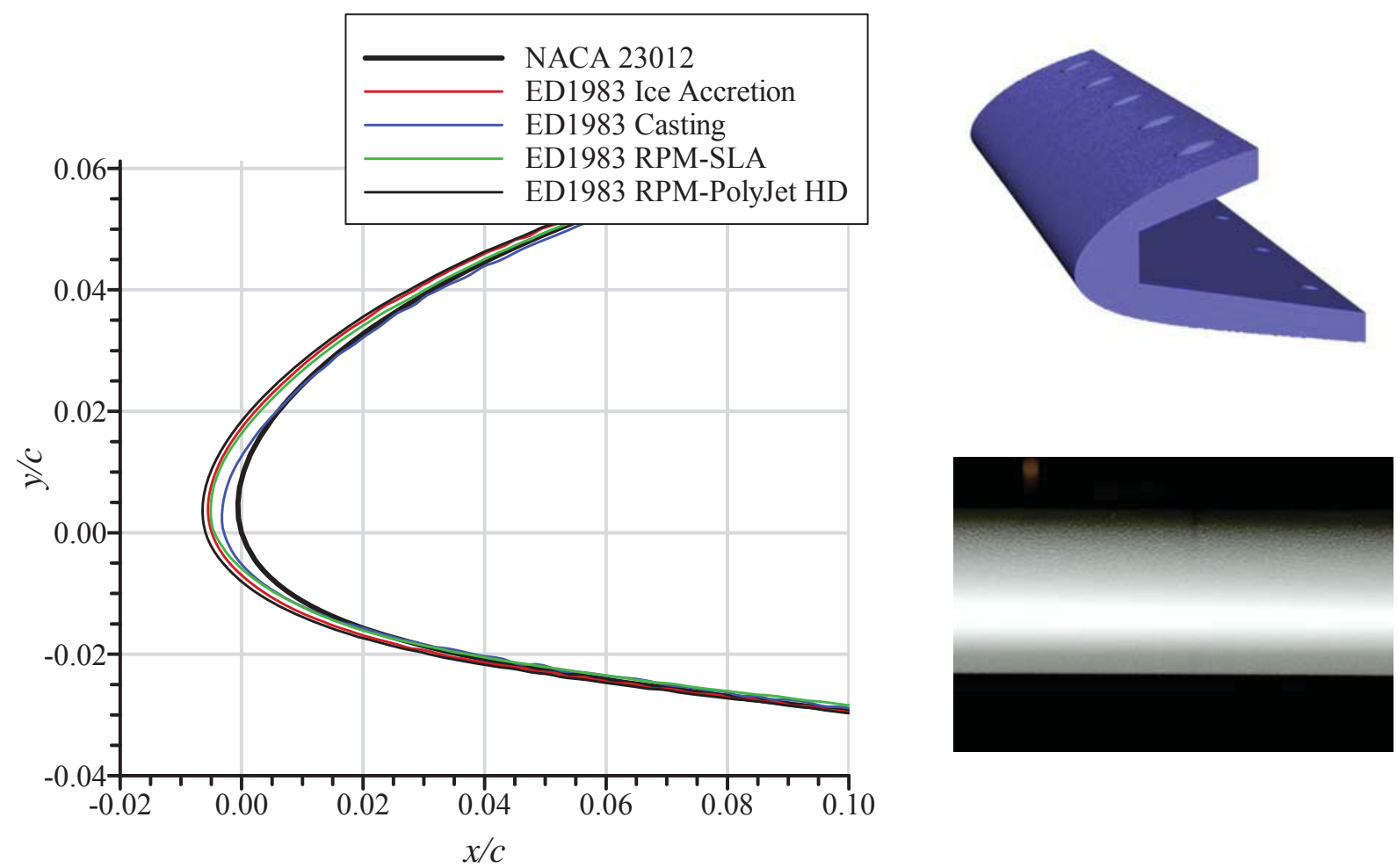

Figure 4. ED1983 roughness ice shape: section cuts extracted from laser-scan data (left); rendering of RPM artificial ice shape (top right) and ice-accretion photograph (bottom right). 


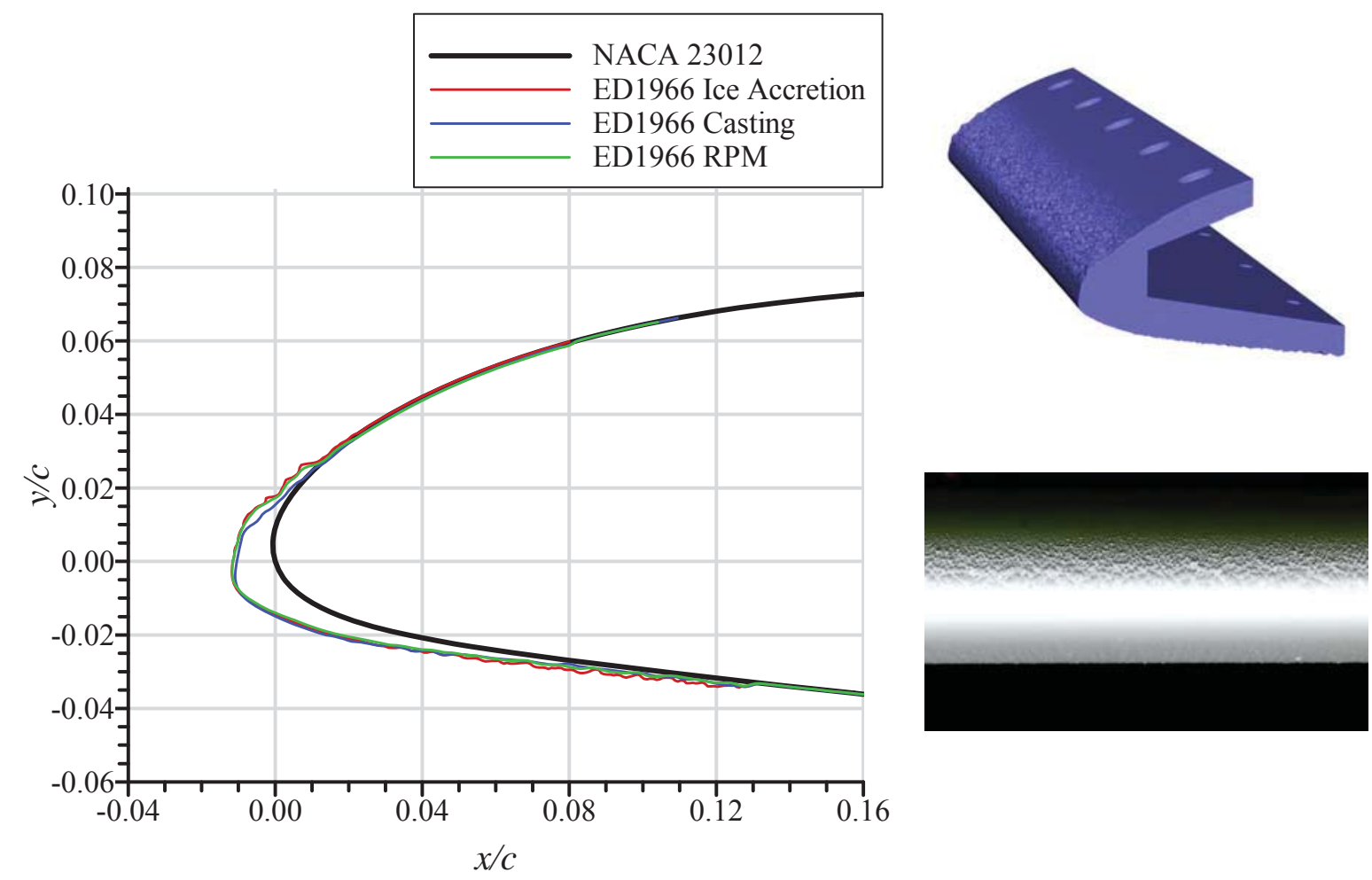

Figure 5. ED1966 streamwise ice shape: section cuts extracted from laser-scan data (left); rendering of RPM artificial ice shape (top right) and ice-accretion photograph (bottom right).

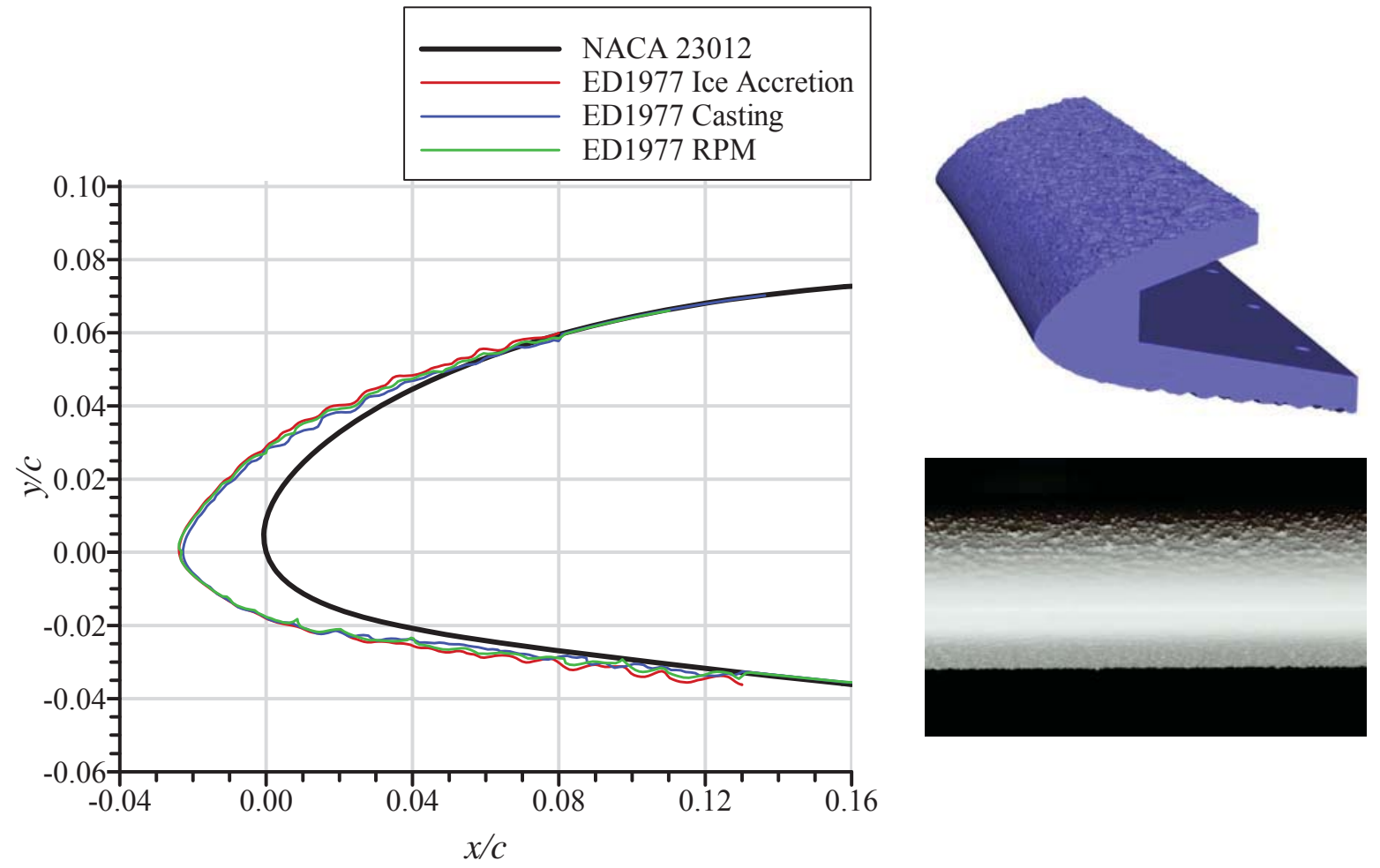

Figure 6. ED1977 streamwise ice shape: section cuts extracted from laser-scan data (left); rendering of RPM artificial ice shape (top right) and ice-accretion photograph (bottom right). 


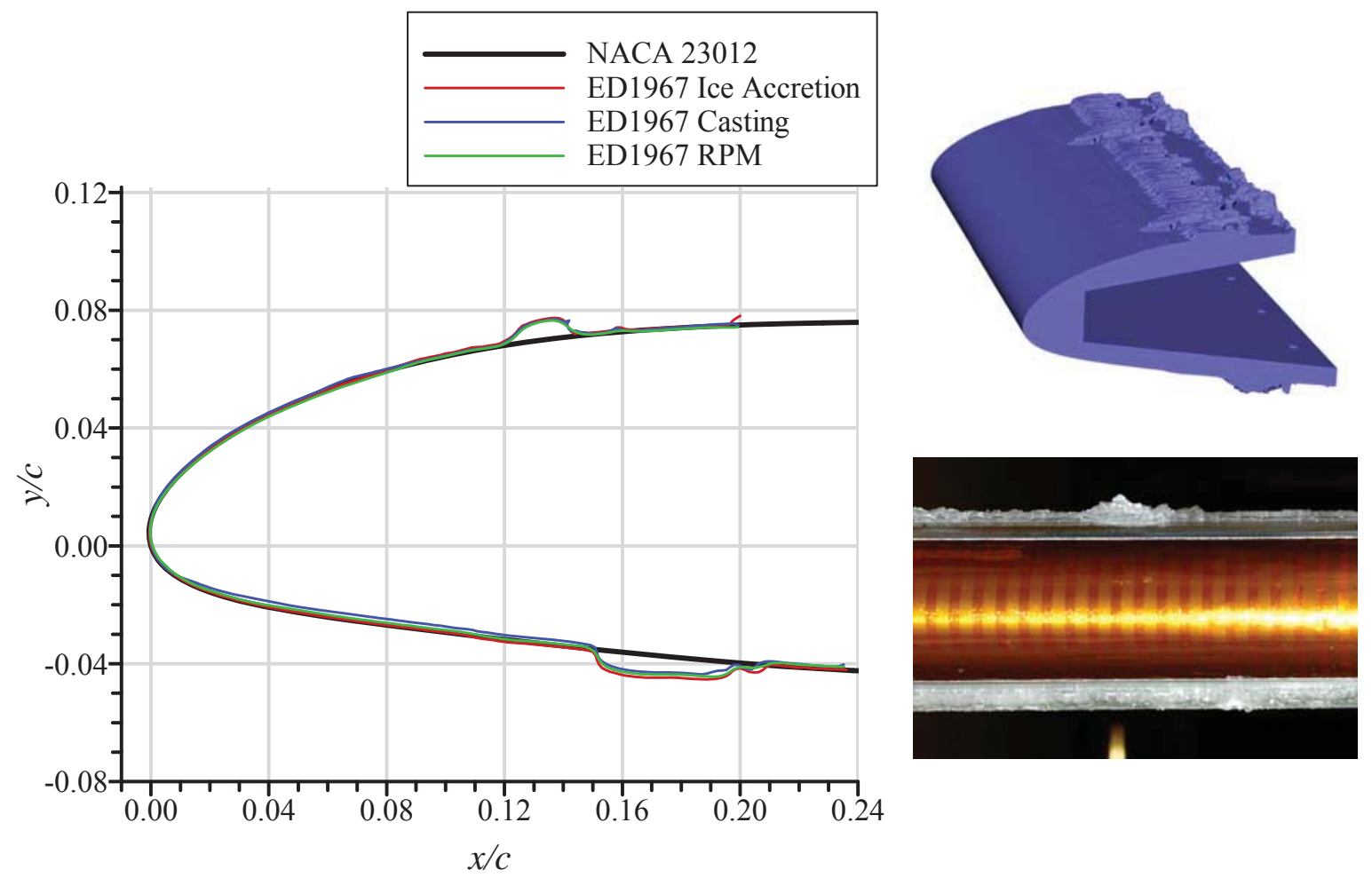

Figure 7. ED1967 spanwise-ridge ice shape: section cuts extracted from laser-scan data (left); rendering of RPM artificial ice shape (top right) and ice-accretion photograph (bottom right).

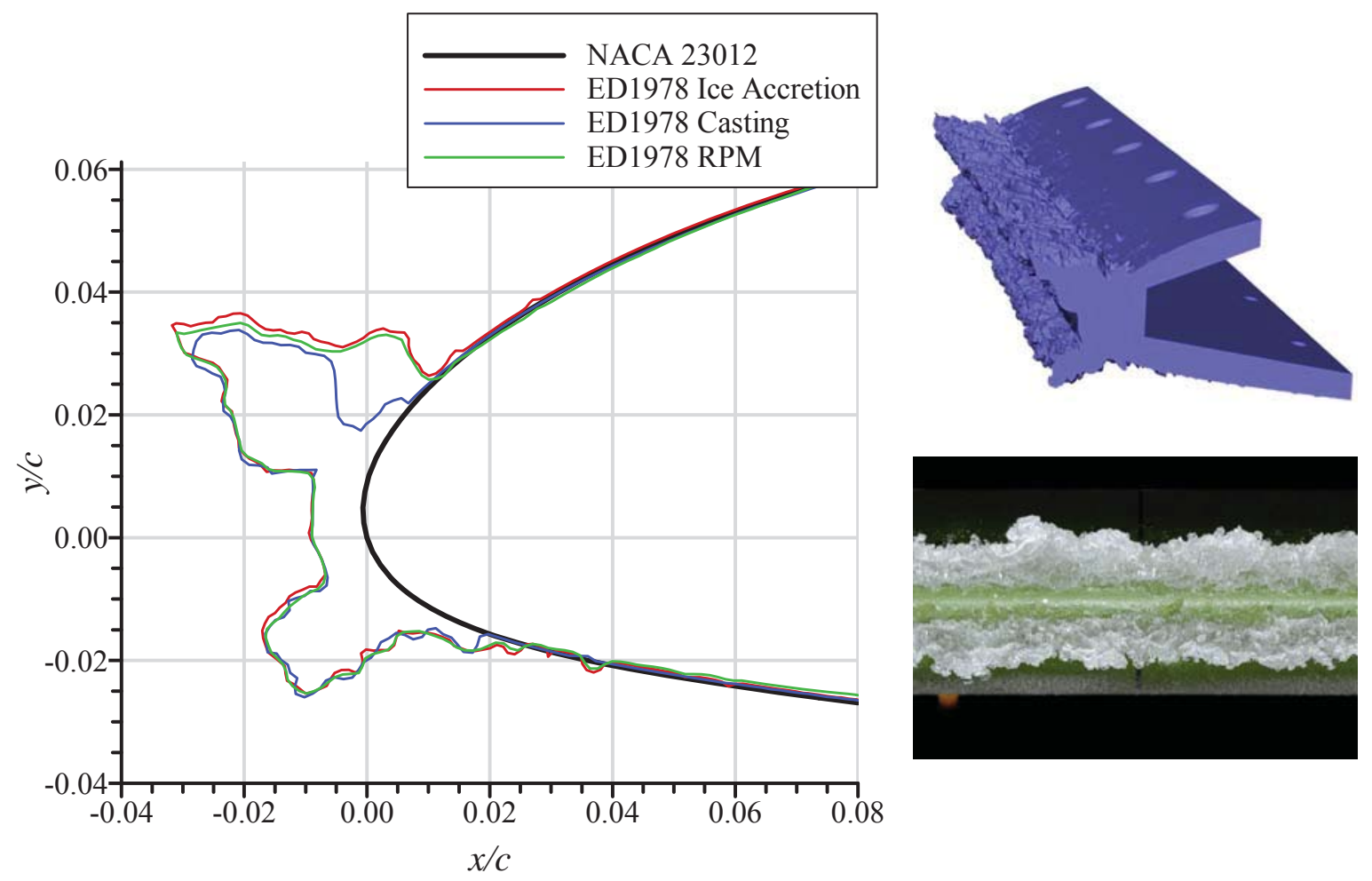

Figure 8. ED1978 horn-ice shape: section cuts extracted from laser-scan data (left); rendering of RPM artificial ice shape (top right) and ice-accretion photograph (bottom right). 


\section{Results}

The main objective of this research was to evaluate the combined accuracy of the laser scanning/rapid prototyping process for iced-aerodynamic simulation. The effect of the ice shape on airfoil performance is compared for both a casting simulation and the corresponding RPM simulation generated from the laser-scan data. As described in the Introduction, the ice casting has been considered the best simulation of the actual ice accretion for dry-air aerodynamic testing. Therefore, the RPM simulation is compared against the casting simulation as the accepted standard. These comparisons are shown for each of the ice shapes described in the previous section after a brief presentation of the clean airfoil results.

\section{A. Clean Airfoil}

A series of clean-airfoil experiments were performed to ensure that the experimental apparatus yielded results consistent with Broeren et al. ${ }^{5}$ and Busch. ${ }^{14}$ The NACA 23012 airfoil lift, pitching-moment and drag coefficient variation with angle of attack is shown in Fig. 9 for both the present data and previous data from Busch. ${ }^{14}$ There was excellent agreement in the lift coefficient and pitching-moment coefficients based upon the integrated surface pressure. In Fig. 9, the maximum lift coefficient was 1.49 for the present data compared to 1.48 for Busch. ${ }^{14}$ The stalling angle of attack was $14.4 \mathrm{deg}$. for both data sets. Individual surface pressure distributions at identical angles of attack were also compared and demonstrated equally good agreement. There were larger differences in the drag coefficient between the two data sets. In general, the present data had higher drag coefficient. The reason for this was not investigated in detail. The differences were attributed to changes in the model surface condition and alignment of the removable leading edges. Since the clean airfoil drag is highly dependent upon the surface condition, any deterioration in the surface condition, or small misalignments in the removable leading edge could result in increased drag. Furthermore, any simulated ice shape would have significantly larger flow disturbance thus minimizing any issues with the clean model surface condition. Therefore, the disagreement in the clean airfoil drag did not compromise the objectives of the present experiments.
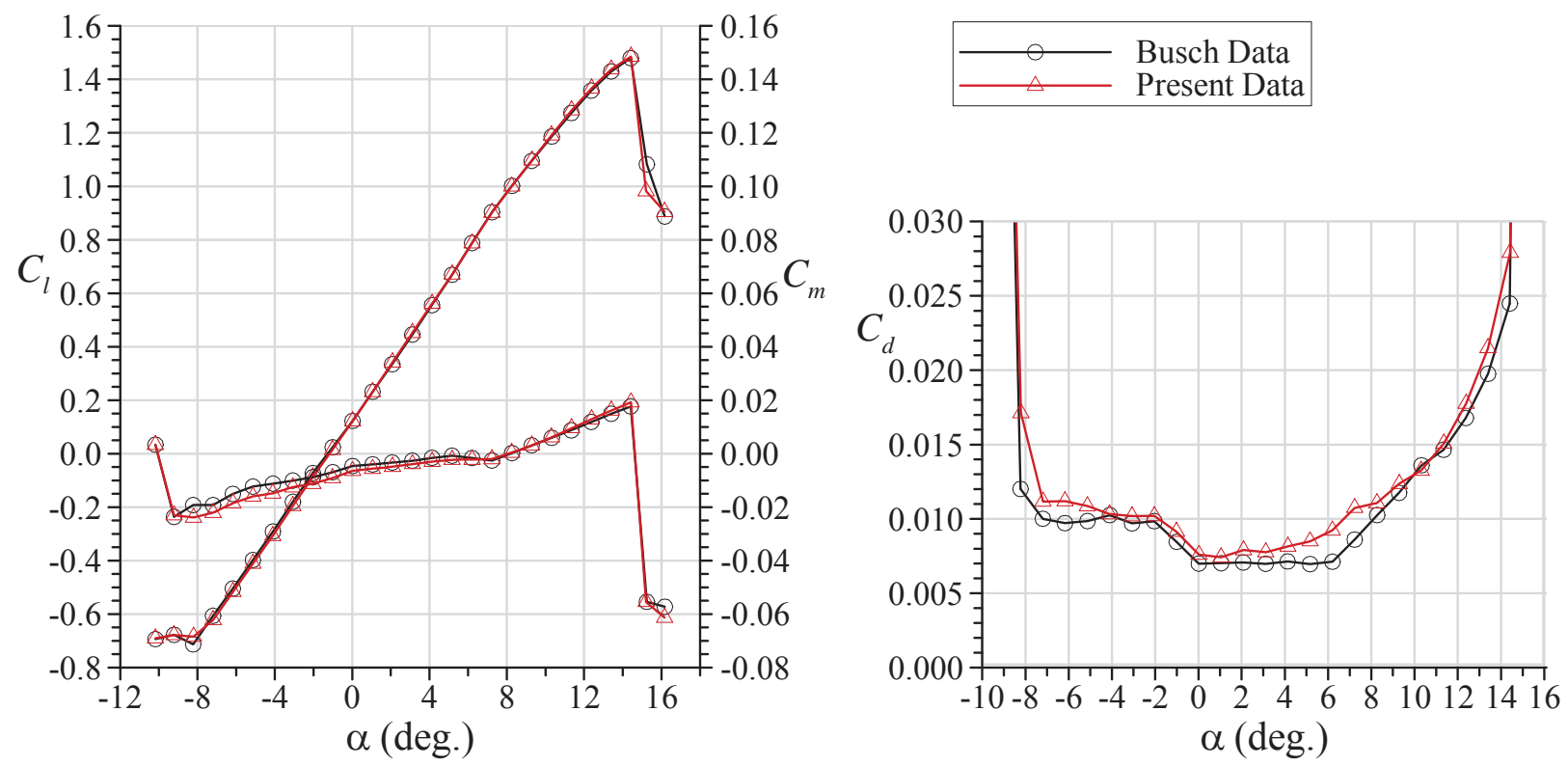

Figure 9. Clean NACA 23013 airfoil aerodynamic performance comparison for the present data with past results from Busch $^{14}$ at $R e=1.8 \times 10^{6}$ and $M=0.18$.

\section{B. Ice Roughness}

The aerodynamic results presented in Fig. 10 show the NACA 23012 lift, pitching-moment and drag coefficients plotted against angle of attack for the clean airfoil and for the ED1974 roughness simulated with the casting and the RPM shape. This relatively small amount of roughness had a large effect on the airfoil performance. For the casting simulation, $C_{l, \max }$ and $\alpha_{\text {stall }}$ were reduced to 1.04 and 10.3 deg., respectively. Overall, the agreement in aerodynamic performance between the casting and the RPM simulations is considered to be very good. The RPM 
simulation had slightly lower $C_{l, \max }=1.01$ at the same stalling angle. This lower $C_{l, \max }$ value was preceded by a small decrease in the lift-curve slope and accompanying higher drag beginning at approximately $\alpha=7 \mathrm{deg}$.

To facilitate comparisons in drag coefficient, Busch et al. ${ }^{20}$ developed a parameter to compare $C_{d}$ over an appropriate angle of attack range. The angle of attack range was that over which $C_{l}$ varied approximately linearly with $\alpha$. The parameter, $\Delta C_{d, r m s}$, is presented as a percentage and is computed by determining the root-mean-square of the percent difference between the casting $C_{d}$ and the corresponding RPM simulation $C_{d}$ at each angle of attack in the pre-defined linear range (a total of $N$ angles of attack):

$$
\Delta C_{d, r m s}=\sqrt{\frac{\sum_{i=1}^{N}\left(\frac{C_{d, r p m}^{i}-C_{d, \text { casting }}^{i}}{C_{d, \text { casting }}^{i}} \times 100 \%\right)^{2}}{N}}
$$

For the ED1974 case, $\Delta C_{d, r m s}$ was $3.8 \%$ calculated on the interval $-4 \leq \alpha \leq 8 \mathrm{deg}$. This value is very low indicating excellent agreement between the drag coefficient of the casting simulation and the RPM simulation. A summary of the key performance-based parameters is provided in Table 3 for comparison. Previous reports ${ }^{5,20-23}$ have tabulated these parameters for artificial ice shapes using different simulation methods having varying degrees of geometric fidelity representing the ice accretion. The results reported in Table 3 for the ED1974 RPM configuration are very good compared to these previous results, further supporting the excellent aerodynamic comparison between the casting and RPM simulations.
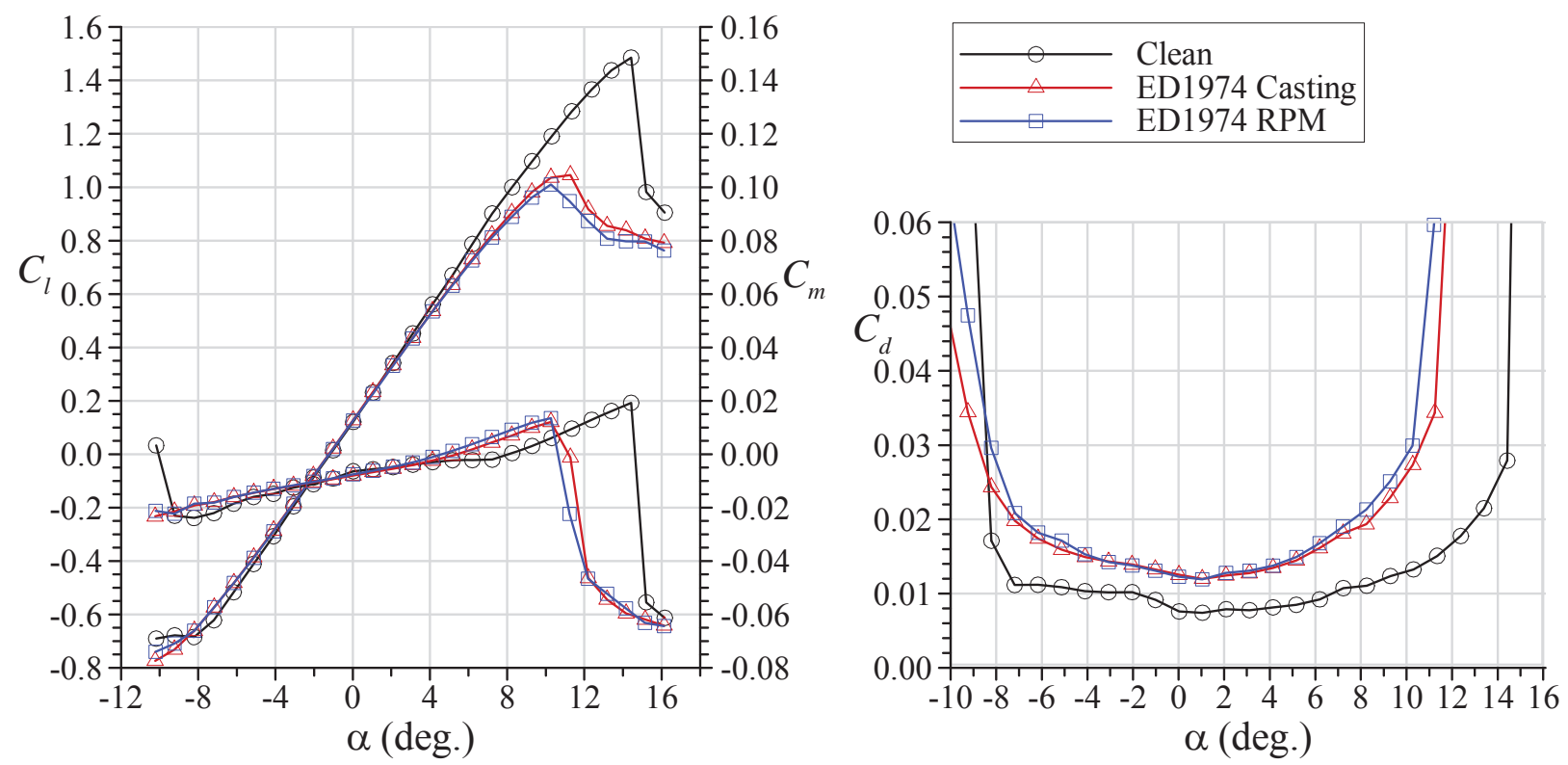

Figure 10. Aerodynamic performance comparison for the ED1974 roughness with casting and RPM simulations on the NACA 23012 airfoil at $R e=1.8 \times 10^{6}$ and $M=0.18$.

Table 3 Summary of Aerodynamic Accuracy for the RPM Simulations.

\begin{tabular}{|c|c|c|c|c|}
\hline $\begin{array}{c}\text { Ice-Shape } \\
\text { Configuration } \\
\end{array}$ & $\begin{array}{l}\text { RPM } C_{l, \text { max }}- \\
\text { Casting } C_{l, \text { max }} \\
\end{array}$ & $\begin{array}{c}\text { RPM } \alpha_{\text {stall }}- \\
\text { Casting } \alpha_{\text {stall }}(\text { deg. }) \\
\end{array}$ & $\Delta C_{d, r m s}$ & $\begin{array}{r}\alpha \text {-range for } \\
\Delta C_{d, \text { rms }}(\text { deg. }) \\
\end{array}$ \\
\hline ED1974 RPM & $-0.026(-2.5 \%)$ & -0.01 & $3.8 \%$ & $-4 \leq \alpha \leq 8$ \\
\hline ED1983 RPM-SLA & $0.071(6.3 \%)$ & 1.03 & $11.1 \%$ & $-4 \leq \alpha \leq 8$ \\
\hline ED1983 RPM-PolyJet HD & $0.126(11.2 \%)$ & 1.04 & $12.5 \%$ & $-4 \leq \alpha \leq 8$ \\
\hline ED1966 RPM & $-0.001(-0.1 \%)$ & 0.00 & $2.9 \%$ & $-4 \leq \alpha \leq 8$ \\
\hline ED1977 RPM & $0.002(0.2 \%)$ & 0.00 & $2.5 \%$ & $-4 \leq \alpha \leq 8$ \\
\hline ED1967 RPM & $-0.042(-2.9 \%)$ & -1.01 & $5.0 \%$ & $-4 \leq \alpha \leq 8$ \\
\hline ED1978 RPM & $-0.034(-4.8 \%)$ & -0.03 & $10.0 \%$ & $-4 \leq \alpha \leq 6$ \\
\hline
\end{tabular}


While the overall performance results shown in Fig. 10 and key parameters summarized in Table 3 represent two measures of the aerodynamic simulation accuracy, it is also important to consider flowfield details. In this investigation, flowfield differences were assessed through comparison of the surface pressure distributions and surface-oil flow visualization. An example of the former is shown in Fig. 11 for each of the configurations at $\alpha=$ $9.3 \mathrm{deg}$. The comparison between the airfoil with the casting and the airfoil with the RPM shape is very good, with $C_{p}$ being virtually identical, except in the leading-edge region. Differences here were attributable to differences in the individual roughness element geometry relative to the location of the pressure orifice. Compared to the clean airfoil $C_{p}$, the data show flowfield behavior that is typical for ice roughness. The simulated ice roughness led to a reduction in the suction pressure on the upper surface from the leading edge downstream to $x / c \approx 0.20$. There was also a divergence of $C_{p}$ downstream of $x / c \approx 0.85$ that is consistent with boundary-layer separation near the airfoil trailing edge. The presence of this trailing-edge separation was confirmed in the surface-oil flow visualization results. Taken together, these results demonstrate the capability of the laser scanning to accurately measure the small roughness features for the ED1974 ice accretion, as well as the ability of the stereolithography RPM to accurately reproduce those same roughness features on the artificial ice shape.

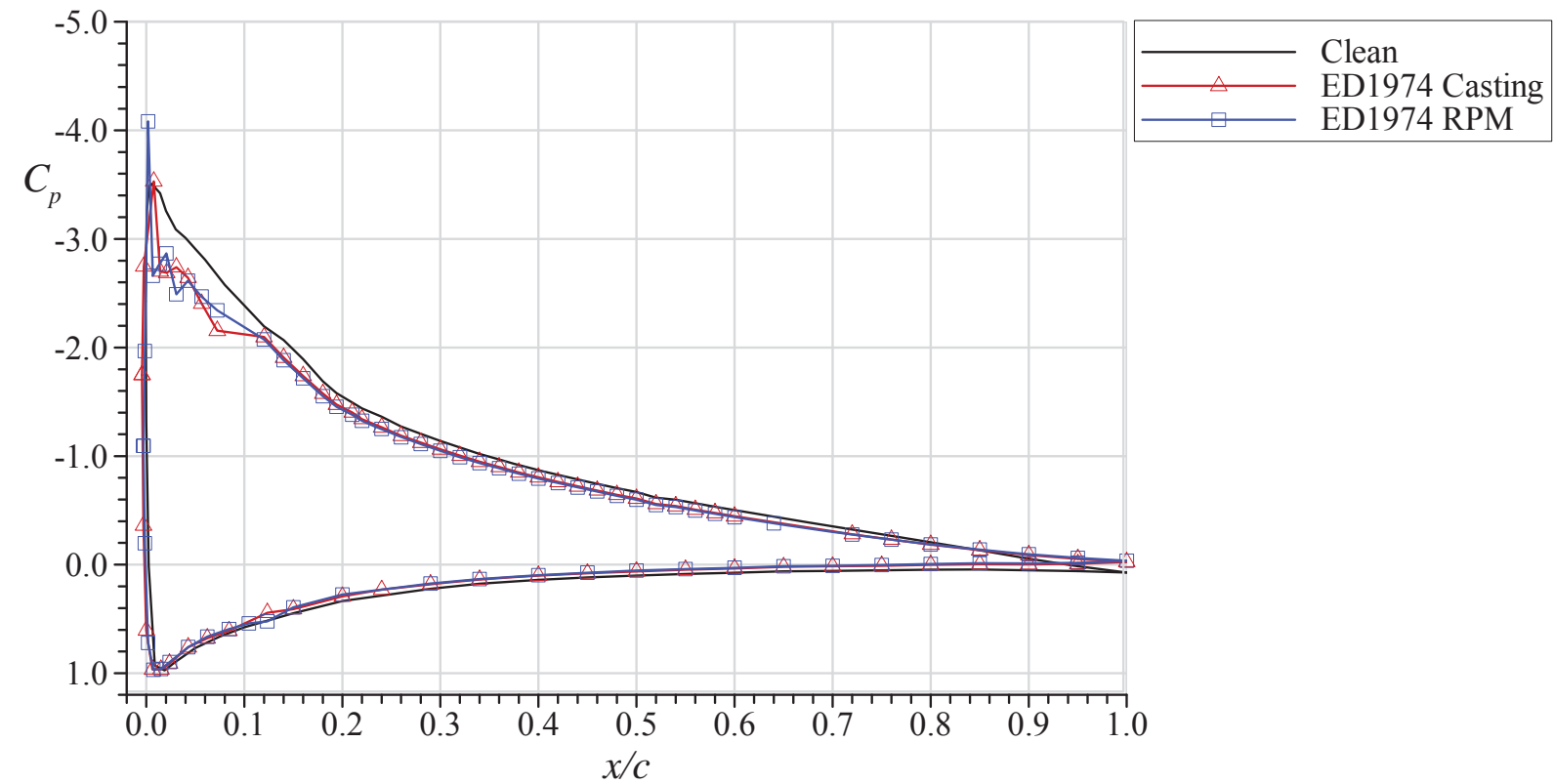

Figure 11. Pressure distribution comparison for the ED1974 roughness with casting and RPM simulations on the NACA 23012 airfoil at $\alpha=9.3 \mathrm{deg}$., $R e=1.8 \times 10^{6}$ and $M=0.18$.

There are practical limitations in terms of the roughness sizes than can be measured and reproduced in an RPM artificial ice shape. The ED1983 case was selected in order to assess these practical limitations. This ice accretion was the most challenging case owing to the very small-scale roughness associated with the icing condition. The lift, pitching-moment and drag coefficient data plotted in Fig. 12 show more significant differences among the casting, stereolithography and PolyJet HD simulations than was previously observed for the ED1974 case. For the airfoil with the ED1983 casting simulation, $C_{l, \max }$ and $\alpha_{\text {stall }}$ were reduced from the clean airfoil case to 1.12 and 11.3 deg., respectively. As noted in Table 3, the SLA simulation resulted in a $C_{l, m a x}$ that was $6.3 \%$ higher than the casting while $C_{l, \max }$ for the PolyJet HD simulation was $11.2 \%$ higher with a corresponding increase in stall angle of approximately one degree for both configurations. There were also significant differences in drag coefficient over a large angle of attack range. These differences are quantified in terms of the $\Delta C_{d, r m s}$ parameter evaluated on the interval $-4 \leq \alpha \leq 8$ deg. in Table 3. The $\Delta C_{d, r m s}$ values of $11.1 \%$ and $12.5 \%$ for the SLA and PolyJet HD shapes were significantly larger than the $3.8 \%$ reported for the ED1974 case.

The distribution of surface pressure is plotted in Fig. 13 for each of the ED1983 configurations at $\alpha=9.3$ deg. The plot shows that the largest differences in $C_{p}$ between the casting configuration and the RPM configurations were observed in the upper-surface suction pressures from the leading edge downstream to $x / c \approx 0.10$. In this region, $C_{p}$ for the RPM configurations more closely matched that of the clean airfoil than for the casting configuration. This 
provides further evidence that the small roughness associated with the ice accretion was not accurately simulated by the laser scan and RPM approach for this ice accretion case.
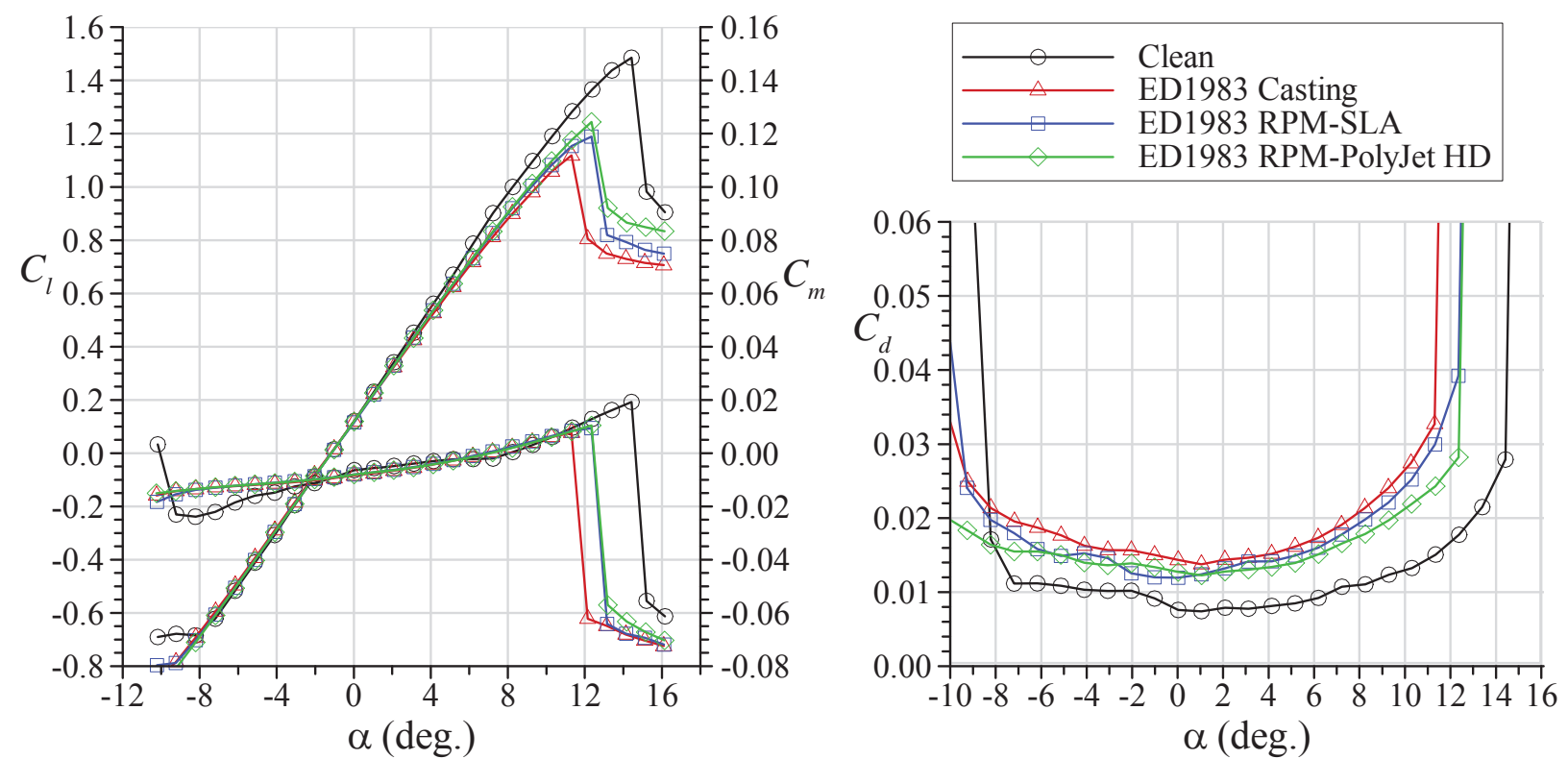

Figure 12. Aerodynamic performance comparison for the ED1983 roughness with casting and RPM simulations on the NACA 23012 airfoil at $R e=1.8 \times 10^{6}$ and $M=0.18$.

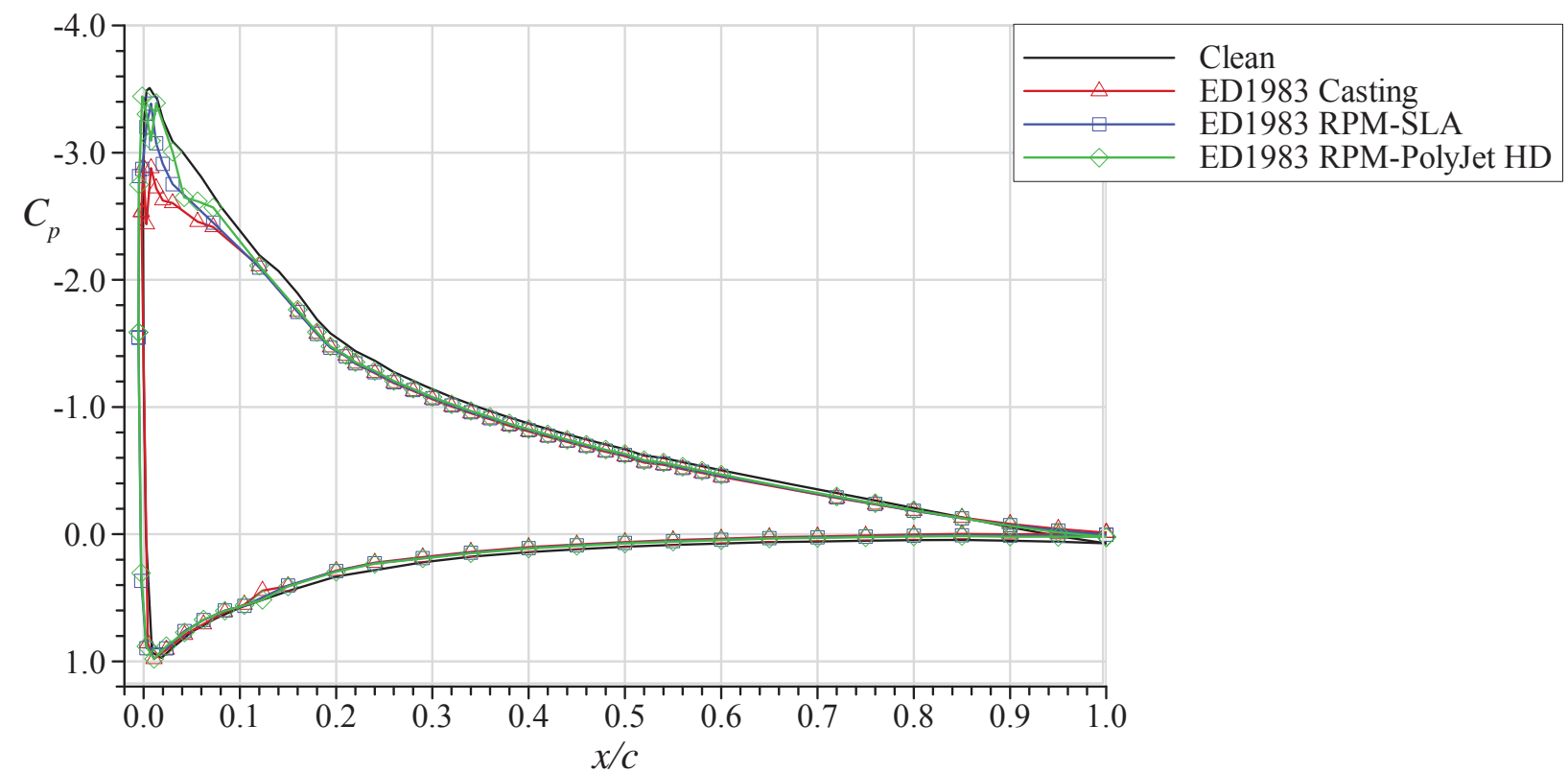

Figure 13. Pressure distribution comparison for the ED1983 roughness with casting and RPM simulations on the NACA 23012 airfoil at $\alpha=9.3 \mathrm{deg}$., $R e=1.8 \times 10^{6}$ and $M=0.18$.

Quantifying the size and distribution of small ice roughness is very difficult. Figure 14 shows images taken from the laser-scan surfaces for the ED1974 and ED1983 ice accretion. While qualitative, these images do show the differences in the roughness characteristics between these two cases. For the ED1974 case, the typical roughness sizes estimated form the scan data were on the order of 0.010 to 0.015 inches $(0.25$ to $0.38 \mathrm{~mm})$. This size is within both the stated accuracy of the laser-scanner measurement system and stereolithography prototyping method. On the other hand, the typical roughness sizes for the ED1983 case estimated from the scan data were an order of 
magnitude smaller, in the range of 0.001 to 0.0015 inches $(0.025$ to $0.038 \mathrm{~mm})$. This size range is at the accuracy limit of the laser-scanning measurement system and below the accuracy of either the stereolithography or PolyJet HD prototyping methods. In future work, the roughness size and distribution should be better quantified in order to further document the limitations of the laser scan and RPM approach. As noted by McClain and Kreeger, ${ }^{24}$ image analysis techniques have been used in the past to determine the dimensions of roughness elements from photographic images. These methods are laborious and not practical to process a large number of cases. McClain and $\mathrm{Kreeger}^{24}$ demonstrated a method for determining roughness size characteristics utilizing the high-resolution laser-scan data of the type described in this paper. This method could be applied to these data in order to better characterize the roughness size distribution and better quantify the limit of the laser scan/RPM approach.

ED1974 Ice-Accretion Photograph

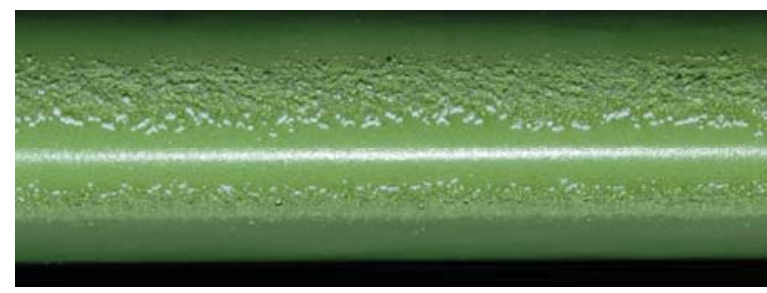

ED1974 Laser-Scan Surface Data Image

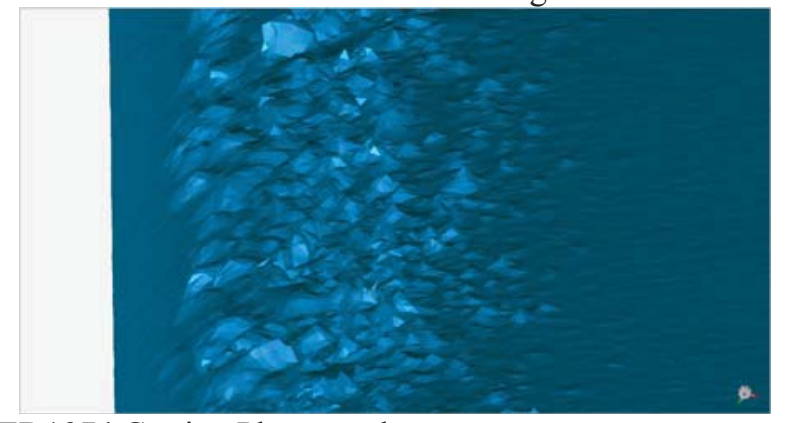

ED1974 Casting Photograph

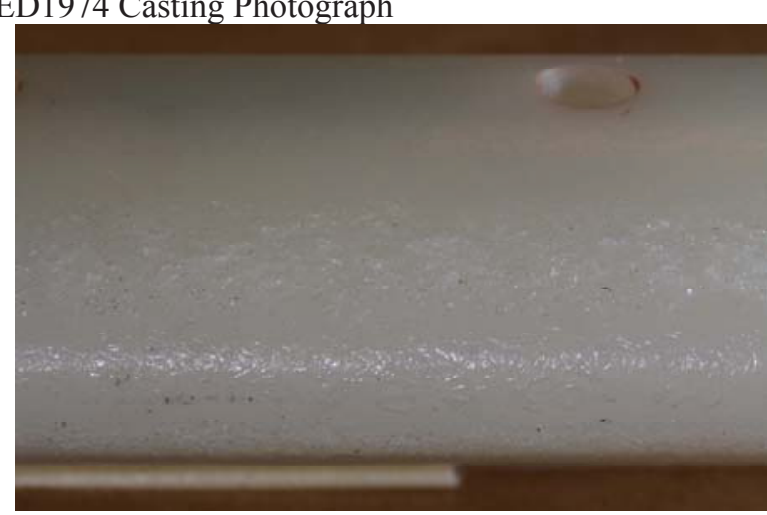

ED1983 Ice-Accretion Photograph

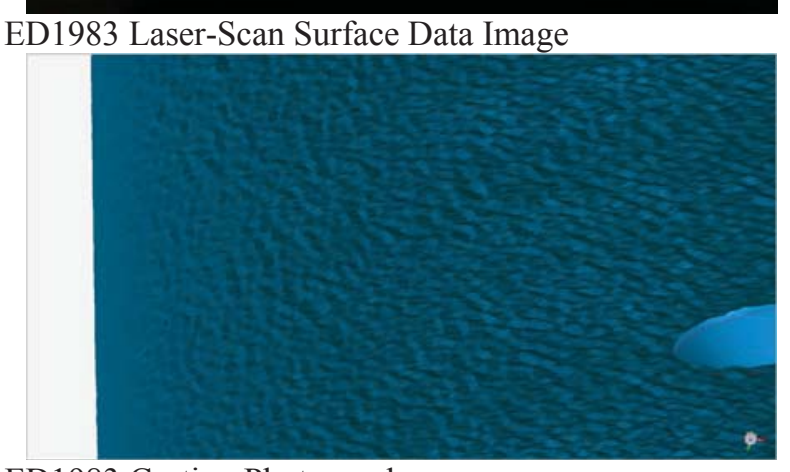

ED1983 Casting Photograph

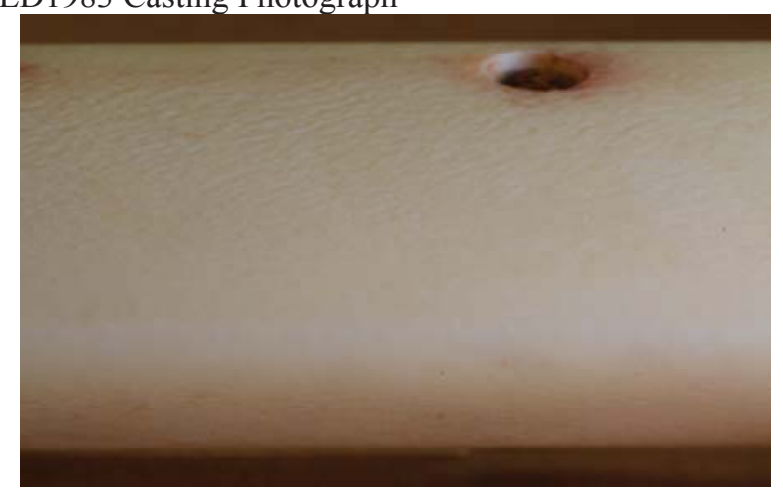

Figure 14. Images of surface roughness for the ED1974 (left) and ED1983 (right) ice accretions.

\section{Streamwise Ice}

Two streamwise ice cases were evaluated in this investigation. Aerodynamic results for the ED1966 case are shown in Fig. 15. The stalling characteristics were nearly identical for the airfoil with the casting simulation or with the RPM simulation. Both artificial ice shapes resulted in $C_{l, \max }=1.00$ at $\alpha_{\text {stall }}=10.3 \mathrm{deg}$. It is interesting to note that these values are very similar to the effect of the ED1974 roughness shape on the airfoil stalling characteristics. Aerodynamic results for the ED1977 case are shown in Fig. 16. Once again, the stalling characteristics were nearly identical for the airfoil with the casting simulation or with the RPM simulation. Both artificial ice shapes resulted in $C_{l, \max }=1.04$ at $\alpha_{\text {stall }}=11.3 \mathrm{deg}$. For this case, the stalling angle was one degree higher than for the ED1966 case. 
Comparisons in the iced-airfoil drag between the casting and RPM shapes were also very good for both streamwise ice cases. This comparison is reflected in the very low values of the $\Delta C_{d, r m s}$ parameter summarized in Table 3 . Not surprisingly, a review of the surface pressure data and flow visualization results also demonstrated excellent matching.
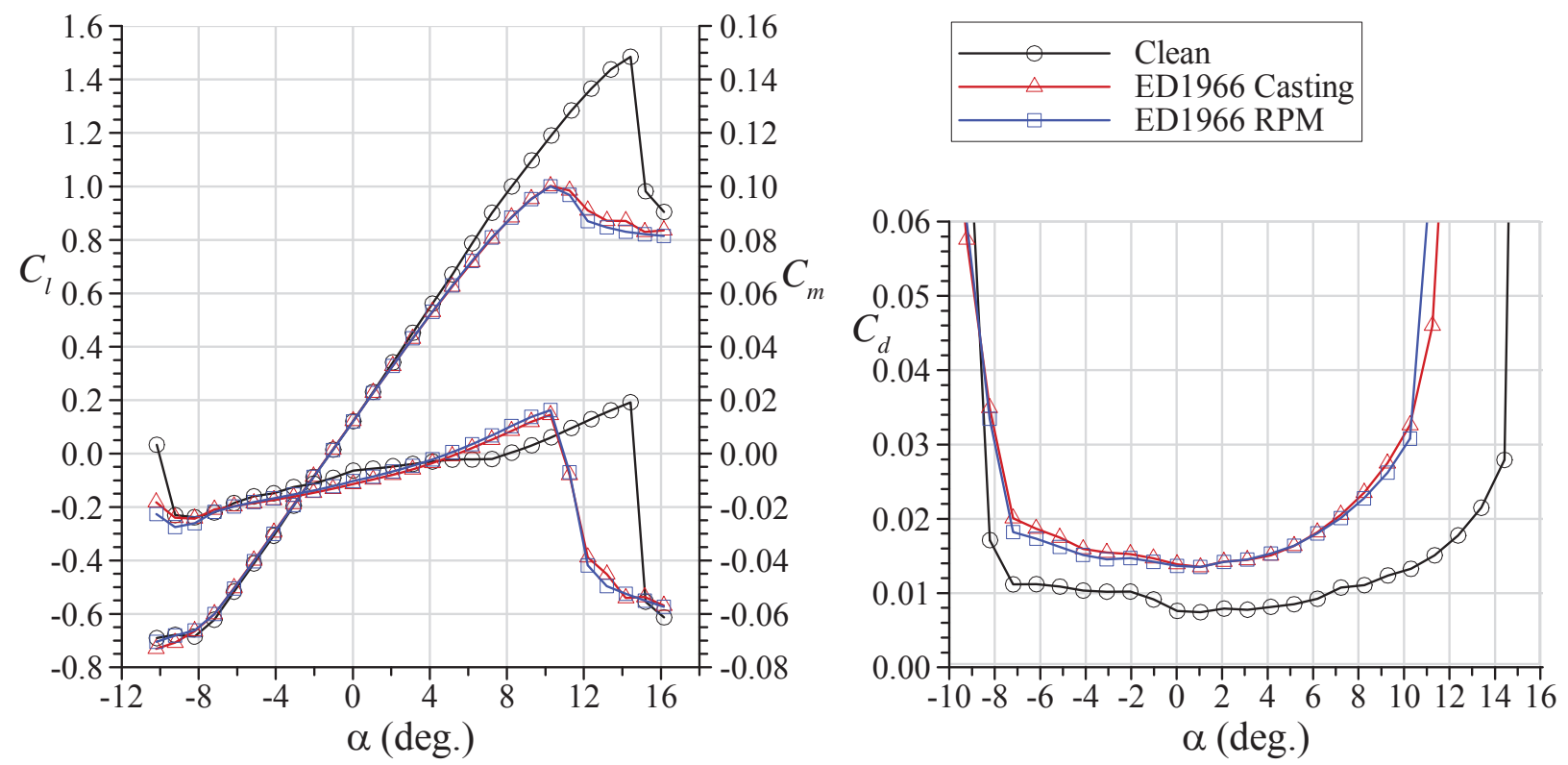

Figure 15. Aerodynamic performance comparison for the ED1966 streamwise ice-shape casting and RPM simulations on the NACA 23012 airfoil at $R e=1.8 \times 10^{6}$ and $M=0.18$.
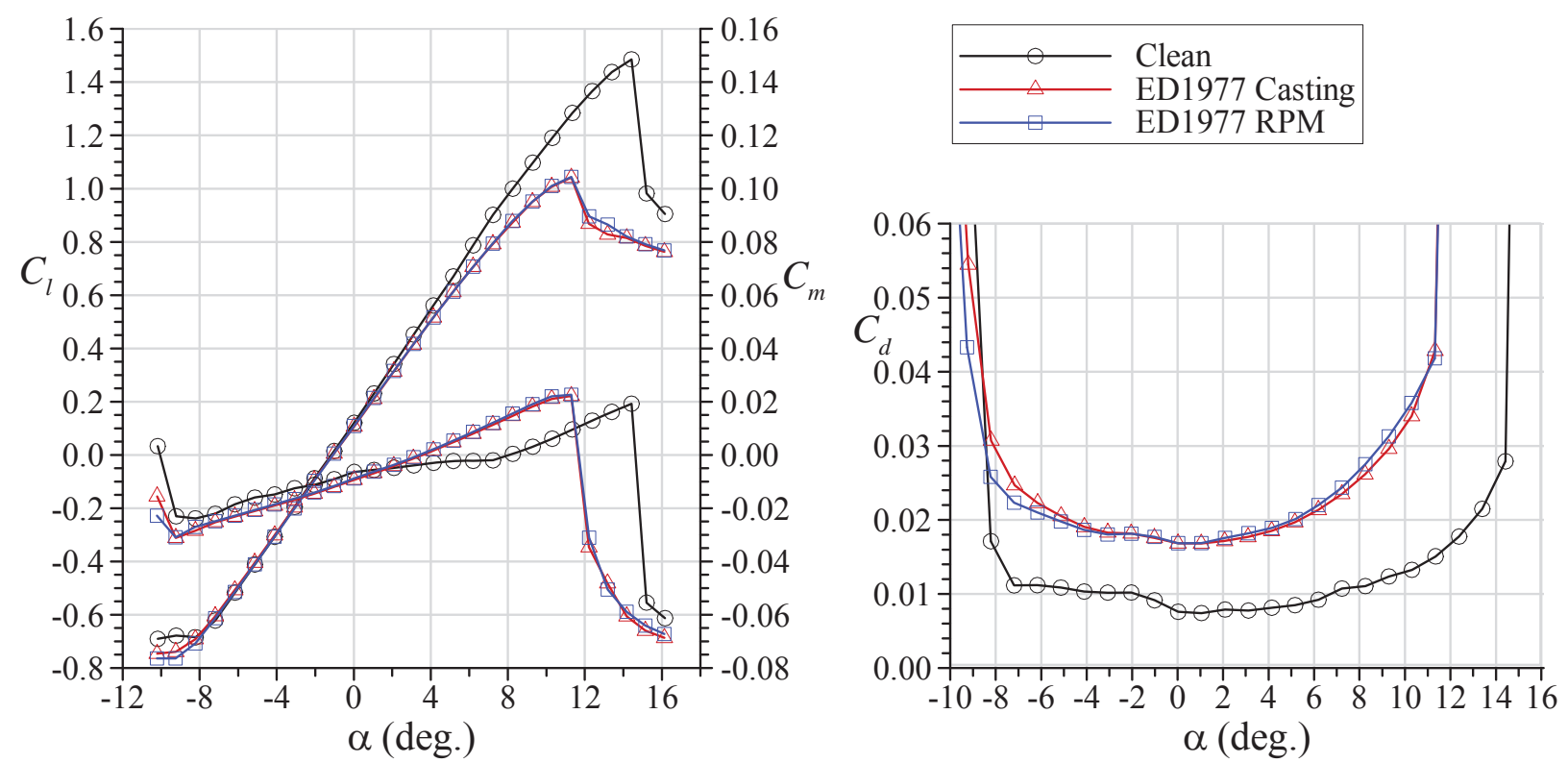

Figure 16. Aerodynamic performance comparison for the ED1977 streamwise ice-shape casting and RPM simulations on the NACA 23012 airfoil at $R e=1.8 \times 10^{6}$ and $M=0.18$.

The aerodynamic simulation of streamwise ice was investigated in detail by Broeren et al. ${ }^{5}$ and Busch et al. ${ }^{14,20,23}$ This type of aerodynamic matching requires accurate reproduction of certain characteristics of the roughness and feather features of the ice accretion. The reproduction of the gross ice shape is actually less 
important for streamwise ice where the main ice accretion tends to be an extension of the airfoil leading edge. The detailed 3-D geometric comparison data (Lee et al. ${ }^{3}$ ) indicated that there was some shrinkage associated with the casting simulation as well as the loss of certain roughness and feather features relative to the original ice accretion Since the reproduction of the gross (or main) ice shape is less aerodynamically important for streamwise ice, the apparent shrinkage had little to no effect on the aerodynamic results. Even though geometric differences were also observed in the roughness and feather regions, these differences were not aerodynamically significant. Therefore, these results further demonstrate the ability of the laser scanning/rapid prototyping method to accurately reproduce the roughness and feather features for this type of ice accretion for the purposes of aerodynamic performance evaluation.

\section{Spanwise-Ridge Ice}

The aerodynamic performance results for the ED1967 spanwise-ridge ice are shown in Fig. 17. The main adverse effect in aerodynamic performance for this ice shape is the large increase in drag coefficient. The maximum lift coefficient was 1.45 for the casting simulation compared to 1.48 for the clean configuration. The stalling angle for the airfoil with the casting simulation was increased by approximately two degrees to $16.4 \mathrm{deg}$. This type of aerodynamic behavior with short spanwise ridge ice was documented in detail by Whalen et al. ${ }^{25-28}$ and Broeren et al. ${ }^{29-31}$ The spanwise-ridge geometry in this case acts to delay stall relative to the clean airfoil at this Reynolds number. However, at increased Reynolds number, the clean airfoil maximum lift coefficient and stall angle would both increase, while the iced-airfoil performance would be expected to remain approximately the same. ${ }^{31}$ For example, at $R e=16.0 \times 10^{6}$ and $M=0.20$, the clean NACA 23012 has $C_{l, \max }=1.82$ and $\alpha_{\text {stall }}=18.1$ deg. ${ }^{5,31}$ At this Reynolds number, the spanwise-ridge ice accretion would have a significant effect on the airfoil performance (as would the other ice accretion cases previously described).
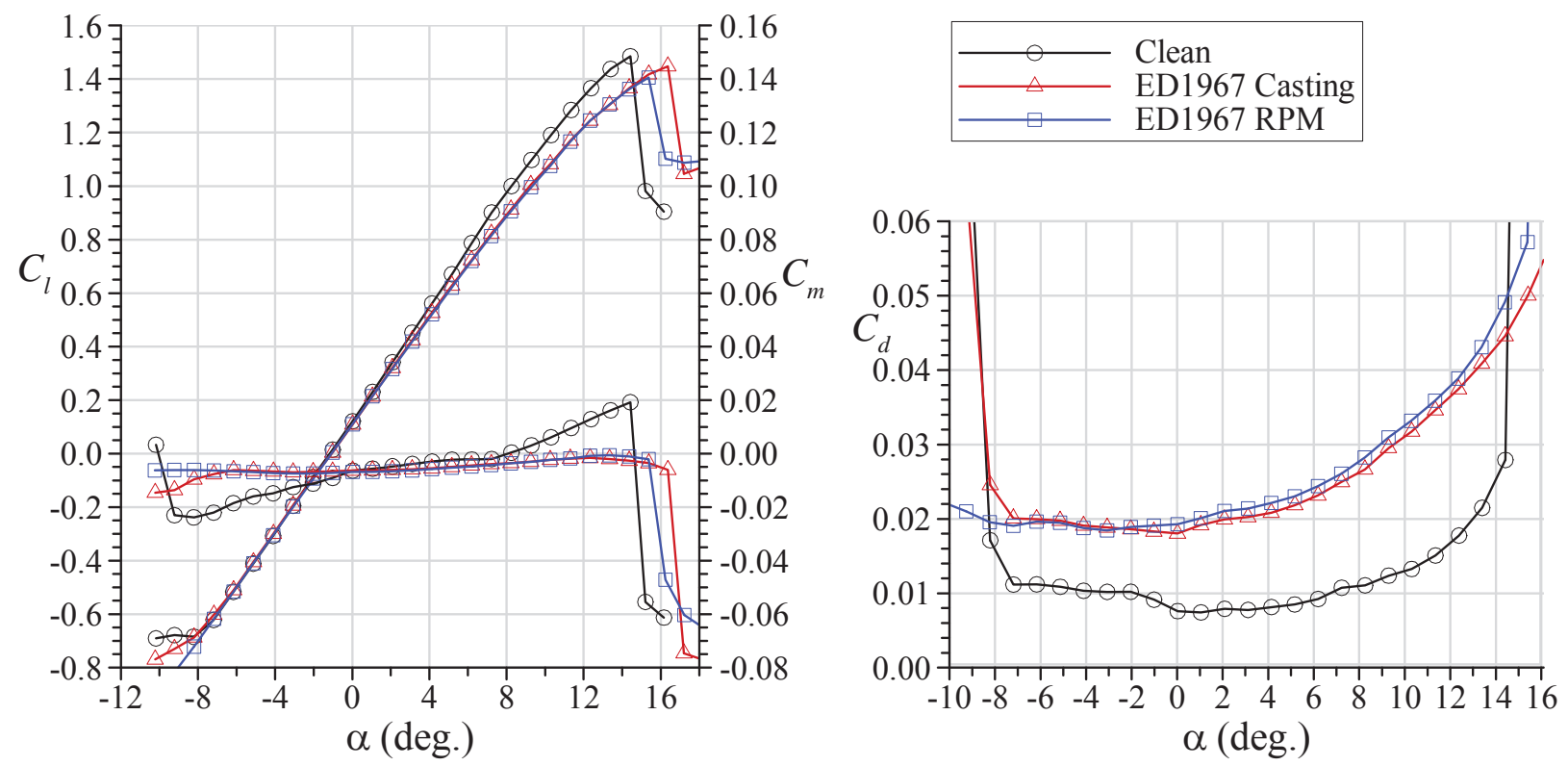

Figure 17. Aerodynamic performance comparison for the ED1967 spanwise-ridge ice-shape casting and RPM simulations on the NACA 23012 airfoil at $R e=1.8 \times 10^{6}$ and $M=0.18$.

The spanwise-ridge geometry in this case is similar to runback ice accretion that is observed on airfoils and wings equipped with thermal ice protection systems that provide continuous heat input to the leading edge. Runback ice accretion occurs when the amount of heat being supplied to the leading edge is less than the amount required to evaporate all of the impinging water. The water that does not evaporate "runs back" downstream and freezes, typically on an unheated portion of the wing. Broeren et al..$^{5}$ summarize the significant aerodynamic factors. Because the ice ridge is located well downstream of the airfoil leading edge, a boundary layer develops on the smooth leading-edge region upstream of the ridge. The characteristics of this boundary layer then depend upon many factors including the airfoil geometry, pressure distribution and Reynolds number. For airfoils like the NACA 
23012 with high leading-edge suction pressure, an ice ridge located farther downstream would be located in a region where there would be a significant adverse pressure gradient on the clean airfoil. The resulting implication for aerodynamic simulation is that the artificial ice shapes must replicate much of the fine details of the runback ice accretion geometry. ${ }^{31}$ Therefore, the good agreement in aerodynamic performance between the casting and RPM simulations shown in Fig. 17 implies that there was also good agreement in the geometry of these two simulations. This favorable comparison is also reflected in the performance metrics listed in Table 3. References 5, 29-31 provide additional listings of these parameters for various spanwise-ridge ice simulations further supporting this evaluation.

Comparisons of the surface pressure distributions and surface-oil flow visualizations were also performed to gauge the simulation accuracy. The pressure distribution comparison in Fig. 18 for $\alpha=6.2$ deg. clearly shows the near-identical match between the casting and RPM shape on the airfoil. The pressure distribution is typical for a short spanwise ridge where the main effect is immediately in the vicinity of the ridge itself. On the upper surface, there was a local deceleration of the flow at the upstream extent of the ridge $(x / c \approx 0.11)$, followed by the flow acceleration over the top of the ridge corresponding to the region of minimum pressure $(x / c \approx 0.13)$. Within a short distance downstream of the ridge $(x / c \approx 0.20)$, the pressure distribution was nearly the same as on the clean airfoil. Similar characteristics were also observed for the lower-surface ridge. This indicated that the aerodynamic effect of the ridge was confined locally to its $x / c$ position. The spanwise ridge did not generate large flow separation that would have significantly altered the pressure distribution. In fact, the most significant difference between the casting and RPM simulations occurred on the upper surface, upstream of the ridge. These differences were most likely attributable to the contour accuracy and surface finish of the leading-edge geometry in this region (i.e., $x / c<$ 0.10). As noted in Lee et al., ${ }^{3}$ the contour accuracy in this region was affected by the electrothermal surface heater used to generate the runback ice ridge. Given the factors described in the previous paragraph, such differences could affect the resulting flow over the ridge and subsequent performance. This may explain why the casting simulation had a stall angle one degree higher than for the RPM simulation.

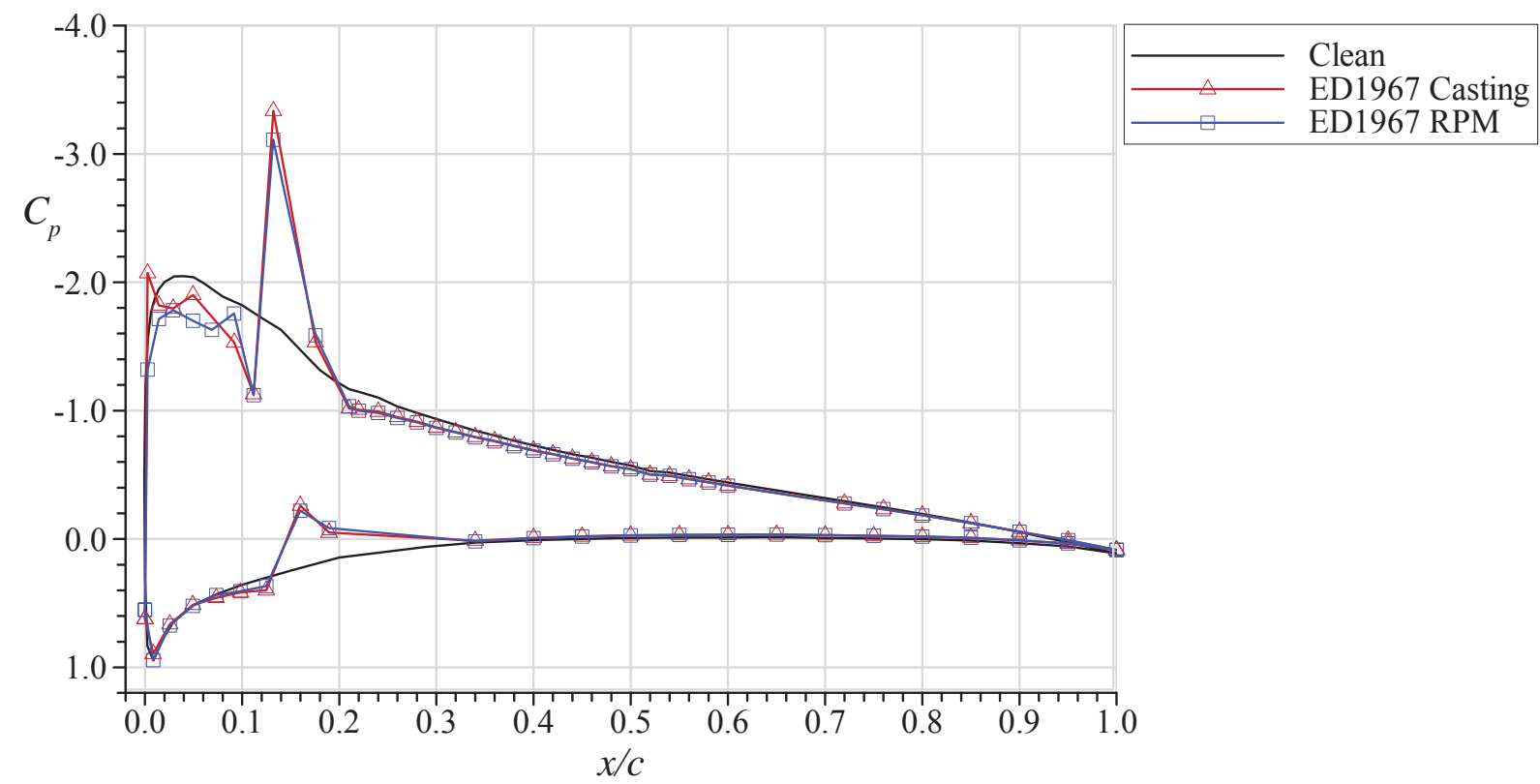

Figure 18. Pressure distribution comparison for the ED1967 spanwise-ridge ice shape with casting and RPM simulations on the NACA 23012 airfoil at $\alpha=6.2 \mathrm{deg}$., $R e=1.8 \times 10^{6}$ and $M=0.18$.

\section{E. Horn Ice}

The aerodynamic performance effects of the horn-ice simulation on the NACA 23012 airfoil are shown in Fig. 19. This case had the largest adverse effect on the airfoil performance of all cases in this investigation. The maximum lift coefficient for the airfoil with the casting was 0.70 at the stalling angle of $7.2 \mathrm{deg}$. For this ice shape the stall angle was taken at $7.2 \mathrm{deg}$. based upon the surface pressure distribution that showed a significant amount of 
lift being generated on the forward portion of the airfoil, despite the break in $C_{m}$ at $\alpha=6.2 \mathrm{deg}$. This is also consistent with the determination of $C_{l, \text { max }}$ and $\alpha_{\text {stall }}$ used in Broeren et al. ${ }^{5}$ Based upon an initial glance at Fig. 19, it may appear that there was good agreement between the performance results for the airfoil with the casting simulation versus the RPM simulation. However, a closer review of the data showed that this was not the case.
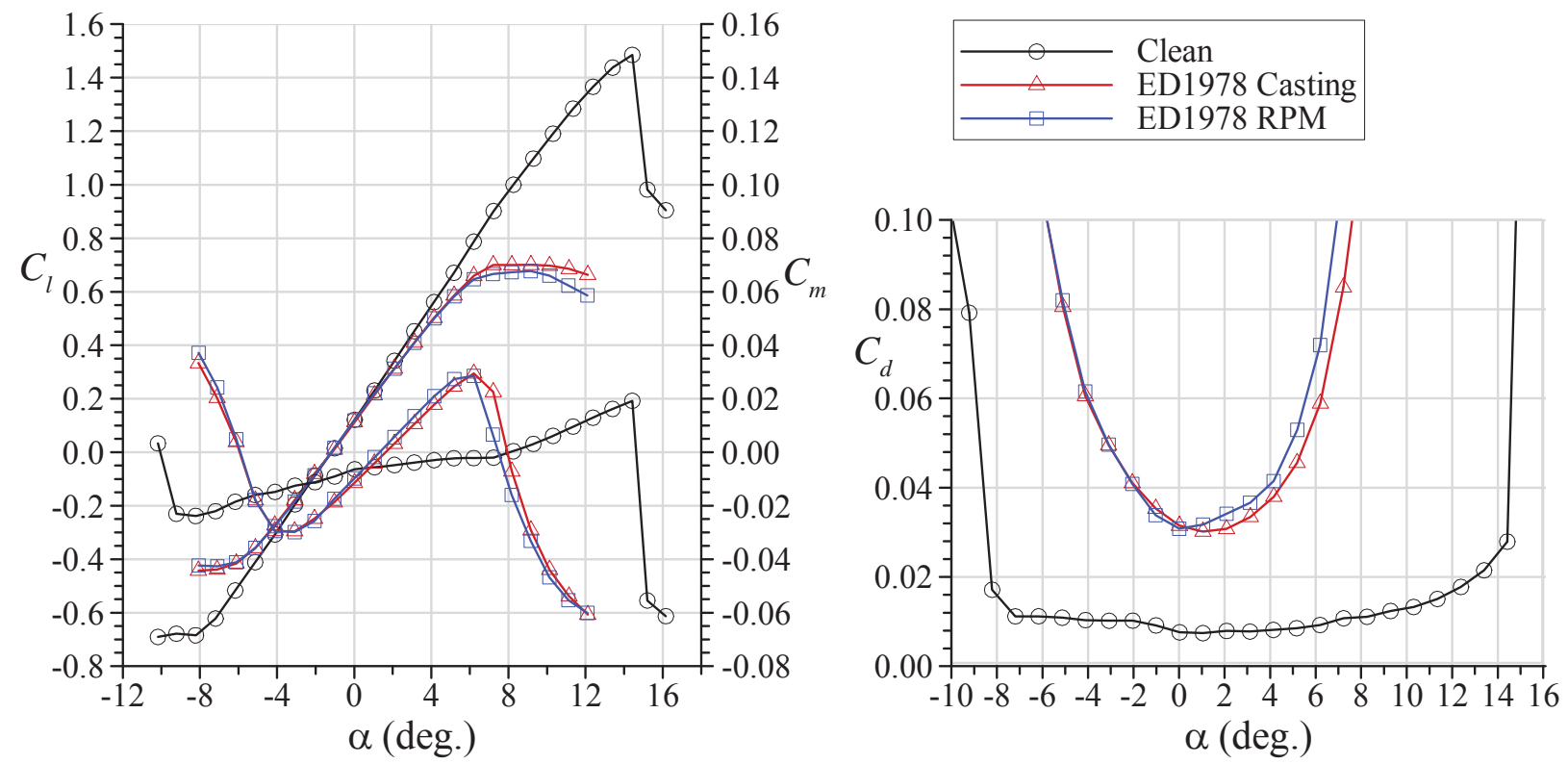

Figure 19. Aerodynamic performance comparison for the ED1978 horn ice-shape casting and RPM simulations on the NACA 23012 airfoil at $R e=1.8 \times 10^{6}$ and $M=0.18$.

The first indication of the poor comparison was based upon an evaluation of the performance-based metrics listed in Table 3. These values were compared to the values reported in Broeren et al. ${ }^{5}$ for similar horn ice accretion. In that report, the artificial ice shapes that were compared to the casting simulation were a 2-D smooth shape and a simple geometry shape. The 2-D smooth shape was a spanwise extrusion of one section cut of the ice accretion while the simple-geometry simulation only had rectangular protuberances (or "spoilers") representing the maximum height and angle of the upper and lower-surface ice horns. Both artificial ice shapes were tested with and without grit roughness applied to the surface, thus representing four different configurations. The resulting performance results were compared to the airfoil with the casting simulation. The variation in $C_{l, \max }$ ranged from $0.2 \%$ for the 2 -D smooth simulation to $-3.0 \%$ for the simple-geometry simulation with added roughness. This range is significantly smaller than the $-4.8 \%$ difference reported in Table 3 for the present study. Since the RPM shape should accurately represent all aerodynamically relevant 3-D features of the ice accretion, a much closer match in $C_{l, \max }$ was expected. Likewise for the $\Delta C_{d, r m s}$ parameter calculated over the same angle of attack interval $(-4.0 \leq \alpha \leq$ 8.0 deg.), the range from Broeren et al. ${ }^{5}$ was $9.4 \%$ to $11.9 \%$. While the present value of $10 \%$ falls within this range, a smaller value was expected. Looking across the range within Table $3, \Delta C_{d, r m s}$ values higher than $10 \%$ were only observed for the ED1983 which has already been described as a poor comparison.

In addition to these performance metrics, the poor comparison for the ED1978 horn ice case was also observed in the surface pressure distributions and flow visualization. An example of the former is shown in Fig. 20 for $\alpha=$ 6.2 deg. The pressure distributions for both the casting simulation and the RPM simulation show the distinctive "plateau" region on the upper surface between the leading edge and $x / c \approx 0.08$. This region of approximately constant pressure corresponds to the separated flow region aft of the upper-surface horn. The key difference in the pressure distributions occurred in the pressure recovery region on the airfoil upper surface. The casting simulation had a more rapid recovery indicating a smaller, or shorter, separated flow region relative to the RPM shape. This observation was corroborated by the surface oil flow visualization images in Fig. 21. These images show the mean chordwise separation bubble reattachment location for each configuration (yellow line). There was some spanwise variation in this location because of the three-dimensional geometry of the artificial ice shapes. For the casting configuration the mean reattachment location was at $x / c \approx 0.20$ compared to $x / c \approx 0.25$ for the RPM configuration. 
The pressure tap row had a spanwise location between 16 and 18-inches from the tunnel floor. At this spanwise location, the mean reattachment location for the casting configuration was still at $x / c \approx 0.20$ compared to $x / c \approx 0.30$ for the RPM configuration. The flow visualization results confirm that the separated flow region for the casting configuration was smaller, or shorter, than for the RPM configuration.

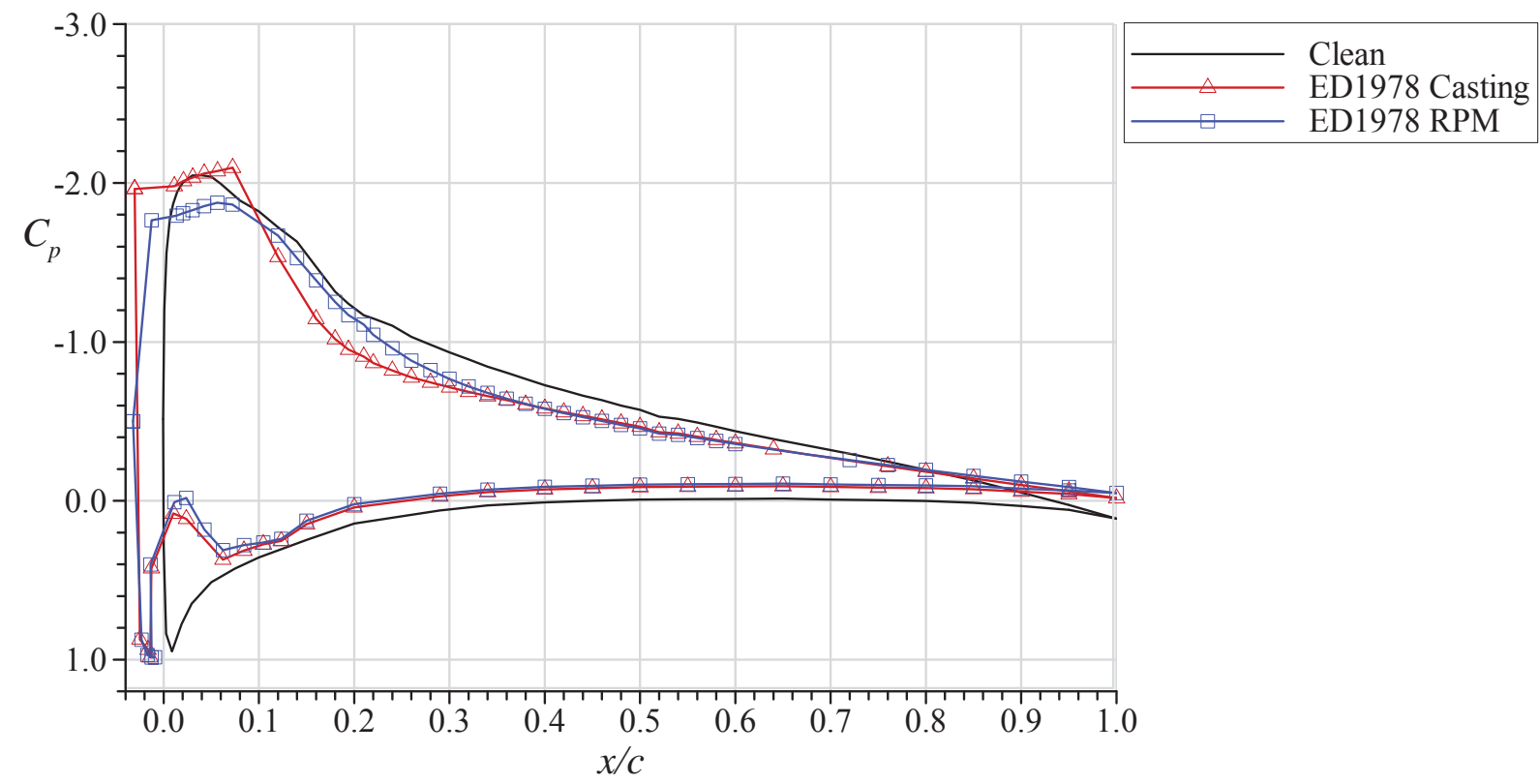

Figure 20. Pressure distribution comparison for the ED1978 horn ice shape with casting and RPM simulations on the NACA 23012 airfoil at $\alpha=6.2 \mathrm{deg}$., $R e=1.8 \times 10^{6}$ and $M=0.18$.
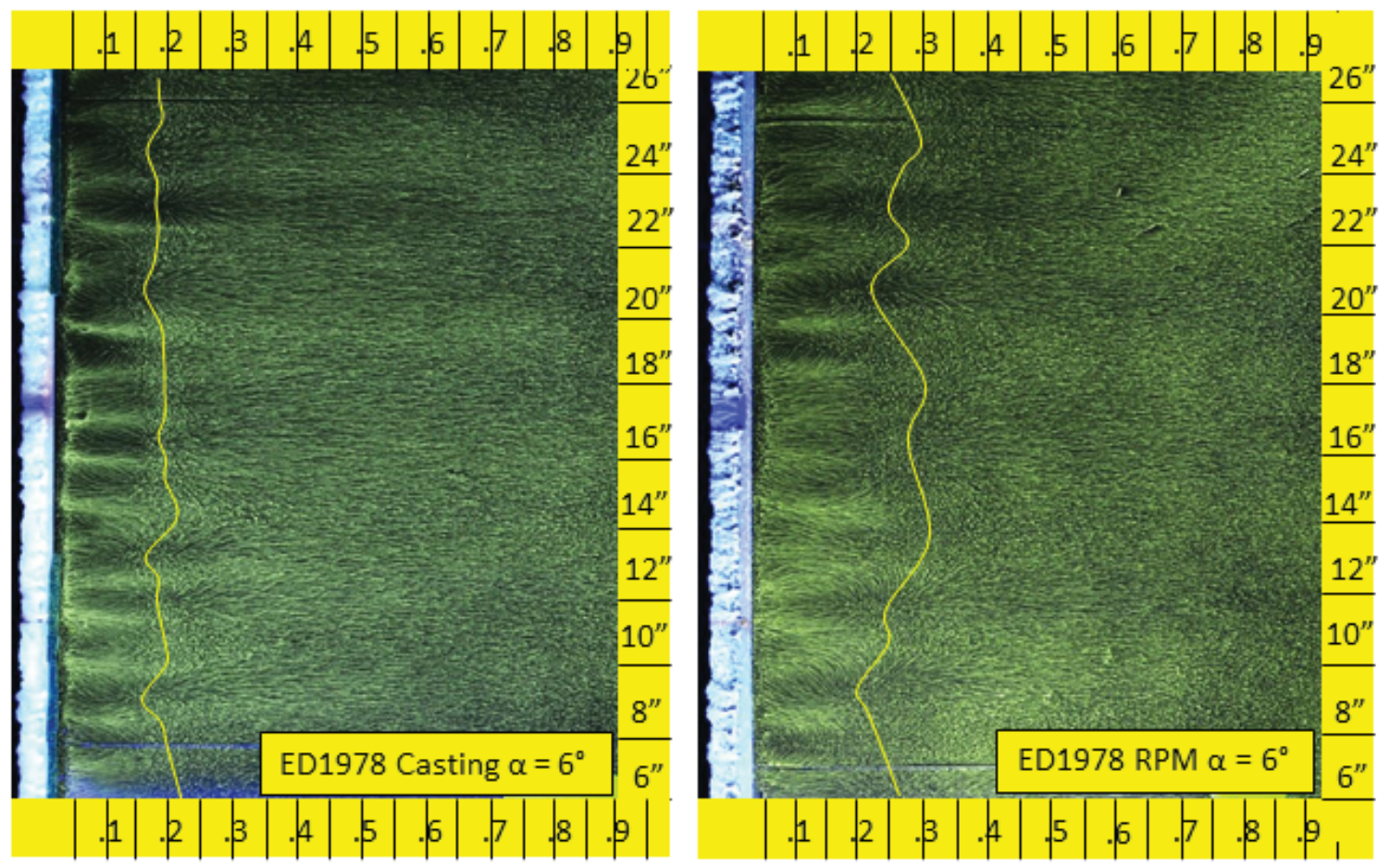

Fig. 21 Surface-oil flow visualization comparison for the ED1978 horn ice shape with casting (left) and RPM (right) simulations on the NACA 23012 airfoil at $\alpha=6.2 \mathrm{deg}$., $R e=1.8 \times 10^{6}$ and $M=0.18$. Yellow line denotes the separation bubble mean reattachment location. Horizontal scales mark the $x / c$ location and vertical scales mark height from the tunnel flow in inches. Figure adapted from Monastero. ${ }^{12}$ 
All of the aerodynamic data presented are consistent with the geometry comparison shown in Fig. 8 where the upper-surface horn of the casting simulation was shorter and more rounded than for the RPM simulation. Both of these factors are known from previous research ${ }^{14,32,33}$ to lead to higher $C_{l, \max }$ and lower $C_{d}$ due to a decrease in the size of the separation bubble. As described in Section II, Lee et al. ${ }^{3}$ indicate that were was some shrinkage and warpage in the casting that led to the geometric differences shown in Fig. 8. These geometry data indicate that the RPM simulation was a better overall match to the ice-accretion geometry.

The aerodynamic evaluation of the horn ice simulation continues to be investigated. Unfortunately, it is not possible to fabricate another casting simulation from the original mold of the ice accretion. This mold no longer exists since it had to be rent asunder in the process of removing the casting from the mold. An alternative approach that will be used instead is to build an RPM simulation based upon the laser-scan data of the casting. These aerodynamic results will more clearly demonstrate the ability of the laser scanning and RPM processes to accurately reproduce horn-ice aerodynamics. It is intended for these aerodynamic data to be included in the NASA Technical Memorandum version of this paper to be completed at a later date. Interested readers are encouraged to visit the website of the NASA Scientific and Technical Information Program where this updated report can be downloaded from the NASA Technical Reports Server.

\section{Conclusion}

Determining the adverse aerodynamic effects due to ice accretion continues to rely on dry-air wind-tunnel testing of artificial, or simulated, ice shapes. Recent developments in ice-accretion documentation methods have yielded a laser-scanning capability that can capture highly three-dimensional features of experimental ice accretion in icing wind-tunnel tests. The three-dimensional laser-scan data can subsequently be used to build fully three-dimensional RPM shapes of the ice accretion. The objective of this paper was to evaluate the aerodynamic accuracy of RPM iceaccretion simulations generated from laser-scan data. Ice-accretion tests were conducted in the NASA IRT using an 18-inch chord, 2-D straight wing with NACA 23012 airfoil section. For the selected ice-accretion cases, a 3-D laser scan was performed to document the ice geometry prior to the molding process. The ice-accretion molds were used to fabricate one set of artificial ice shapes from polyurethane castings. The laser-scan data were used to fabricate another set of artificial ice shapes using rapid-prototype manufacturing such as stereolithography. Aerodynamic performance testing was conducted on an 18-inch chord NASA 23012 airfoil model at a Reynolds number of $1.8 \times 10^{6}$ and a Mach number of 0.18 . The iced-airfoil results with both sets of artificial ice shapes were compared to evaluate the aerodynamic simulation accuracy of the laser-scan data. Consistent with past research, the ice-casting simulation was taken as the accepted standard, or benchmark, to which the RPM shapes were compared. This aerodynamic comparison was a combined evaluation of not only the laser-scanning measurement method, but also the accuracy of the rapid-prototype method used to generate the artificial ice shapes. For the purposes of this paper, uncertainties in the scan data and manufacturing tolerances in the rapid-prototyping method are combined into the resulting artificial ice shape.

The aerodynamic comparisons were performed for two cases of ice roughness (ED1974 and ED1983), two streamwise ice shapes (ED1966 and ED1977), one spanwise-ridge ice shape (ED1967) and one horn-ice shape (ED1978). For four of these six cases, there was excellent agreement in the iced-airfoil aerodynamic performance between the casting and RPM simulations. For example, typical differences in iced-airfoil maximum lift coefficient were less than $3 \%$ with corresponding differences in stall angle of approximately one degree or less. The glaze-ice roughness ice accretion (ED1974) had estimated roughness heights of 0.010 to 0.015 inches $(0.25$ to $0.38 \mathrm{~mm})$. This size is within both the stated accuracy of the laser-scanner measurement system and stereolithography prototyping method. The resulting aerodynamic comparison was very good. One case that exhibited poor comparison was the small rime-ice roughness ice accretion (ED1983). Typical roughness heights in this case were estimated to be in the range of 0.001 to 0.0015 inches $(0.025$ to $0.038 \mathrm{~mm})$. This size range is at the accuracy limit of the laser-scanning measurement system and below the capability of the selected rapid-prototype manufacturing methods. The remaining ice accretion that exhibited poor comparison was the horn-ice case and was attributed to deficiencies in the ice-casting simulation related to shrinkage in the casting process. This case continues to be investigated and additional results will be reported in the NASA Technical Memorandum version of this paper to be completed at a later date.

The aerodynamic simulation accuracy reported in this paper has demonstrated the combined accuracy of the laser-scan and RPM approach to simulating ice accretion for a NACA 23012 airfoil. For several of the ice-accretion cases tested, the aerodynamics is known to depend upon the small, three-dimensional features of the ice. These data show that the laser-scan and RPM approach is capable of replicating these ice features within the reported accuracies 
of the measurement and prototype method; thus providing a new capability for high-fidelity ice-accretion documentation and artificial ice-shape fabrication for icing research.

\section{Acknowledgments}

The Atmospheric Environment Safety Technologies Project of the NASA Aviation Safety Program with Ron Colantonio as project manager provided support for this research. The authors thank the crew of the NASA Icing Research Tunnel for their support of the ice-accretion testing and molding portion of this work. Lloyd Utt provided invaluable assistance with post-processing of the laser-scan data and development of the rapid-prototype artificial ice shapes under the NASA Undergraduate Student Researcher's Program. The Federal Aviation Administration provided support for ice-casting fabrication and wind-tunnel testing at University of Illinois. The authors gratefully acknowledge Jeff Diebold, Brian Woodard, Dave Foley and Mike Bragg at University of Illinois for their contributions to this research.

\section{References}

${ }^{1}$ Lee, S., Broeren, A.P., Addy, H.E., Jr., Sills, R., and Pifer, E.M., "Development of 3-D Ice Accretion Measurement Method," AIAA Paper 2012-2938, June 2012; also NASA/TM-2012-217702, Sept. 2012.

${ }^{2}$ Bosetti, C., Paul, B.P., Jr., Malone, A.M., "Ice Shape Characterization to Aid in Replicating Ice Shapes for Subsequent Analysis," AIAA Paper 2010-7534.

${ }^{3}$ Lee, S., Broeren, A.P., Kreeger, R.E., Potapczuk, M.G., and Utt, L., "Implementation and Validation of 3-D Ice Accretion Measurement Methodology," AIAA $6^{\text {th }}$ Atmospheric and Space Environments Conference, Atlanta, GA, June 16-20, 2014 (submitted for publication).

${ }^{4}$ Reehorst, A.L., and Richter, G.P., "New Methods and Materials for Molding and Casting Ice Formations," NASA TM-100126, Sept. 1987.

${ }^{5}$ Broeren, A.P., Addy, H.E., Jr., Bragg, M.B., Busch, G.T., Guffond, D., and Montreuil, E., "Aerodynamic Simulation of Ice Accretion on Airfoils," NASA/TP-2001-216929, June 2011.

6 Broeren, A.P., Bragg, M.B., and Addy, H.E., Jr., "Effect of Intercycle Ice Accretions on Aerodynamic Performance," Journal of Aircraft, Vol. 41, No. 1, Jan.-Feb. 2004, pp. 165-174.

${ }^{7}$ Addy, H.E., Jr., Broeren, A.P., Zoeckler, J.G., and Lee, S., "A Wind Tunnel Study of Icing Effects on a Business Jet Airfoil,” AIAA Paper 2003-0727, Jan. 2003; also NASA/TM-2003-212124, Feb. 2003.

${ }^{8}$ Papadakis, M., Yeong, H.W., Wong, S.C., Vargas, M., and Potapczuk, M.G., "Aerodynamic Performance of a Swept Wing with Ice Accretions," AIAA Paper 2003-0731, Jan. 2003.

${ }^{9}$ Gile-Laflin, B.E., and Papdakis, M., "Experimental Investigation of Simulated Ice Accretions on a Natural Laminar Flow Airfoil," AIAA Paper 2001-0088, Jan. 2001.

${ }^{10}$ Gregorek, G., Dresse, J.J., and LaNoe, K., "Additional Testing of the DHC-6 Twin Otter Tailplane Iced Airfoil Section in the Ohio State University 7x10 Low Speed Wind Tunnel," NASA/CR-2000-209921/Vol. 2, Sept. 2000.

${ }^{11}$ Addy, H.E., Jr., and Chung, J.J., "A Wind Tunnel Study of Icing Effects on a Natural Laminar Flow Airfoil," AIAA Paper 2000-0095, Jan. 2000; also NASA/TM-2000-209775, Jan. 2000.

${ }_{12}$ Monastero, M.C., "Validation of 3-D Ice Accretion Documentation and Replication Method Including Pressure-Sensitive Paint," M.S. Thesis, Dept. of Aerospace Engineering, Univ. of Illinois at Urbana-Champaign, 2013.

${ }^{13}$ Monastero, M.C., and Bragg, M.B., "Validation of 3-D Ice Accretion Measurement Methodology Using Pressure-Sensitive Paint (PSP)," AIAA $6^{\text {th }}$ Atmospheric and Space Environments Conference, Atlanta, GA, June 1620, 2014 (submitted for publication).

${ }^{14}$ Busch, G.T., "Ice Accretion Aerodynamic Simulation on a Subscale Model" M.S. Thesis, Dept. of Aerospace Engineering, Univ. of Illinois at Urbana-Champaign, 2006.

${ }^{15}$ Kline, S., and McClintock, F.A, "Describing Uncertainties in Single Sample Experiments," Mechanical Engineering, Vol. 75, No. 1, 1953, pp. 3-8.

${ }^{16}$ Coleman, H.W., and Steele, W.G., Experimentation and Uncertainty Analysis for Engineers, WileyInterscience, New York, 1989, pp.40-118.

${ }^{17}$ Allen, H. J., and Vincenti, W.G., "Wall Interference in a Two-Dimensional-Flow Wind Tunnel, With Consideration of the Effect of Compressibility," NACA Report 782, 1944.

${ }^{18}$ Barlow, J.B., Rae, W.H., Jr., and Pope, A., Low-Speed Wind Tunnel Testing, John Wiley \& Sons, 1999, pp. 328-366. 
19 Bragg, M.B., Broeren, A.P., and Blumenthal, L.A., "Iced-Airfoil Aerodynamics," Progress in Aerospace Sciences, Vol. 41, No. 5, July 2005, pp. 323-418.

${ }^{20}$ Busch, G.T., Broeren, A.P., and Bragg, M.B., "Aerodynamic Fidelity of Sub-scale Two-Dimensional Ice Accretion Simulation,” AIAA Paper 2008-7062, Aug. 2008.

${ }^{21}$ Broeren, A.P., Whalen, E.A., Busch, G.T., and Bragg, M.B., “Aerodynamic Simulation of Runback Ice Accretion," Journal of Aircraft, Vol. 47, No. 3, May-June 2010, pp. 924-939, also AIAA Paper 2009-4261, June 2009.

${ }^{22}$ Broeren, A.P., Whalen, E.A., Busch, G.T., and Bragg, M.B., “Aerodynamic Simulation of Runback Ice Accretion," U.S. Dept. of Transportation/Federal Aviation Administration Rept. DOT/FAA/AR-09/26, Dec. 2009, also NASA/TM-2010-215676, Mar. 2010.

23 Busch, G.T., "Experimental Study of Full-Scale Iced-Airfoil Aerodynamic Performance using Subscale Simulations," Ph.D. dissertation, Dept. of Aerospace Eng., Univ. of Illinois, Urbana, Illinois, 2010.

${ }^{24}$ McClain, S.T., and Kreeger, R.E., "Assessment of Ice Shape Roughness Using a Self-Organizing Map Approach," AIAA Paper 2013-2546, June 2013.

${ }^{25}$ Whalen, E.A., Broeren, A.P., and Bragg, M.B., "Considerations for Aerodynamic Testing of Scaled Runback Ice Accretions," AIAA Paper 2006-0260, 44 ${ }^{\text {th }}$ Aerospace Sciences Meeting and Exhibit, Reno, NV, Jan. 2006.

26 Whalen, E.A, Broeren, A.P., and Bragg, M.B., "Characteristics of Runback Ice Accretion and their Aerodynamic Effects,” U.S. Dept. of Transportation/Federal Aviation Administration Rept. DOT/FAA/AR-07/16, April 2007.

${ }^{27}$ Whalen, E.A., “Aerodynamics of Runback Ice Accretions,” Ph.D. dissertation, Dept. of Aerospace Eng., Univ. of Illinois, Urbana, Illinois, 2007.

${ }^{28}$ Whalen, E.A, Broeren, A.P., and Bragg, M.B., “Aerodynamics of Scaled Runback Ice Accretions," Journal of Aircraft, Vol. 45, No. 3, May-June 2008, pp. 1076-1088.

29 Broeren, A.P., Whalen, E.A., Busch, G.T., and Bragg, M.B., "Aerodynamic Simulation of Runback Ice Accretion," AIAA Paper 2009-4261, June 2009.

${ }^{30}$ Broeren, A.P., Whalen, E.A., Busch, G.T., and Bragg, M.B., “Aerodynamic Simulation of Runback Ice Accretion,” DOT/FAA/AR-09/26, Dec. 2009; also NASA/TM-2010-215676, Mar. 2010.

31 Broeren, A.P., Whalen, E.A., Busch, G.T., and Bragg, M.B., "Aerodynamic Simulation of Runback Ice Accretion," Journal of Aircraft, Vol. 47, No. 3, May-Jun. 2010, pp. 924-939.

32 Busch, G.T., Broeren, A.P., and Bragg, M.B., "Aerodynamic Simulation of a Horn-Ice Accretion on a Subscale Model," AIAA Paper 2007-0087, 45 ${ }^{\text {th }}$ Aerospace Sciences Meeting and Exhibit, Reno, NV, Jan. 2007.

33 Busch, G.T., Broeren, A.P., and Bragg, M.B., "Aerodynamic Simulation of a Horn-Ice Accretion on a Subscale Model," Journal of Aircraft, Vol. 45, No. 2, Mar.-Apr. 2008, pp. 604-613. 